\begin{tabular}{|c|l|}
\hline Title & $\begin{array}{l}\text { Steady state vapor compression refrigeration cycle simul ation for a monoval ent inverter-driven water-to-water heat } \\
\text { pump with a desuperheater for low energy houses }\end{array}$ \\
\hline Author(s) & Blanco, David L.; Nagano, Katsunori; Morimoto, Masahiro \\
\hline Citation & $\begin{array}{l}\text { International Journal of Refrigeration, 35(7), 1833-1847 } \\
\text { https://doi.org/10.1016/.ijrefrig.2012.07.005 }\end{array}$ \\
\hline Issue Date & 2012-11 \\
\hline Doc URL & http://hdl.handle.net/2115/52252 \\
\hline Type & article (author version) \\
\hline File Information & IJR35-7_1833-1847.pdf \\
\hline
\end{tabular}

Instructions for use 


\title{
Steady state vapor compression refrigeration cycle simulation for a monovalent inverter-driven water-to-water heat pump with a desuperheater for low energy houses
}

\author{
David L. Blanco ${ }^{1}$, Katsunori Nagano, Masahiro Morimoto \\ Division of Human Environmental Systems, Graduate School of Engineering. Hokkaido \\ University, N13-W8. Kita Ku, Sapporo 060-8628, Japan
}

\begin{abstract}
A steady-state simulation is presented for a monovalent inverter-driven water-to-water heat pump with a desuperheater. For design-oriented simulations, superheating or subcooling degrees are used as input. However, the proposed simulation only uses the system's refrigerant charge, environmental, and control parameters, which make it particularly useful for off-design evaluations, including the annual performance factor calculation. Block models were used for the compressor and electronic expansion valve, while novel adaptive zone models were used for the heat exchangers. A multivariable error minimization algorithm was used over a sequential component scheme to provide global convergence. The numerical calculations were compared with 118 experimental results. The resulting COP agrees within $10 \%$ for $95.77 \%$ of the data. The mapping results reveal a maximum COP deviation of $8.78 \%$. Computational results for the studied system reveal that a constant degree of superheating might not always maximize the COP.
\end{abstract}

Keywords:

Modeling; Simulation; Heat pump, Compression System; Hot water; Heating

\footnotetext{
${ }^{1}$ Corresponding Author Email: david.blanco.ch@eng.hokudai.ac.jp, david.blanco.ch@gmail.com Tel /Fax: +81-(0)11-706-6285
} 


\begin{tabular}{|c|c|c|c|c|c|}
\hline name & description & units & name & Description & units \\
\hline \multicolumn{6}{|c|}{ Roman characters } \\
\hline$A$ & Area & {$\left[\mathrm{m}^{2}\right]$} & $P i$ & Pitch & {$[\mathrm{m}]$} \\
\hline$A_{0 \ldots 4}$ & Constants & N.D. & $Q$ & Heat transfer & {$[\mathrm{W}]$} \\
\hline $\mathrm{B}_{0 \ldots 2}$ & Constants & N.D. & $R_{c u}$ & Thermal resistance & {$\left[\mathrm{WK}^{-1}\right]$} \\
\hline$C_{p / v}$ & $\begin{array}{l}\text { Specific heat at constant } \\
\text { pressure or volume }\end{array}$ & {$\left[\mathrm{Jkg}^{-1} \mathrm{~K}^{-1}\right]$} & res & Resolution & N.D. \\
\hline$c h$ & Number of channels & N.D. & rug & Rugosity & {$[\mathrm{m}]$} \\
\hline$D$ & External diameter & {$[\mathrm{m}]$} & step & Expansion valve step & N.D. \\
\hline$d$ & Internal diameter & {$[\mathrm{m}]$} & $T$ & Temperature & {$[\mathrm{K}]$} \\
\hline E & Error function & N.D. & th & Thickness & {$[\mathrm{m}]$} \\
\hline eval & Objective function & N.D. & $V$ & Volume & {$\left[\mathrm{m}^{3}\right]$} \\
\hline$f$ & Friction factor & N.D. & $v$ & Specific volume & {$\left[\mathrm{m}^{3} \mathrm{~kg}^{-1}\right]$} \\
\hline freq & $\begin{array}{l}\text { Electrical frequency of } \\
\text { compressor }\end{array}$ & {$[\mathrm{Hz}]$} & vel & Velocity & {$\left[\mathrm{ms}^{-1}\right]$} \\
\hline$G$ & Volumetric flow rate & {$\left[\mathrm{m}^{3} \mathrm{~s}^{-1}\right]$} & $W_{\text {com }}$ & Compression work & {$[\mathrm{W}]$} \\
\hline$H$ & Specific enthalpy & {$\left[\mathrm{Jkg}^{-1}\right]$} & $W_{e l}$ & $\begin{array}{l}\text { Compressor electric } \\
\text { consumption }\end{array}$ & {$[\mathrm{W}]$} \\
\hline$h t$ & Height & {$[\mathrm{m}]$} & $W_{i s}$ & Isentropic work & {$[\mathrm{W}]$} \\
\hline$L$ & Length & {$[\mathrm{m}]$} & $w t$ & Width & {$[\mathrm{m}]$} \\
\hline$\dot{m}$ & Mass flow rate & {$\left[\mathrm{kgs}^{-1}\right]$} & $x$ & Quality & N.D. \\
\hline$M$ & Mass & {$[\mathrm{kg}]$} & & & \\
\hline$M_{\text {charge }}$ & $\begin{array}{l}\text { System's refrigerant mass } \\
\text { charge }\end{array}$ & {$[\mathrm{kg}]$} & & & \\
\hline$M_{\text {tube }}$ & $\begin{array}{l}\text { Connection tubes' } \\
\text { refrigerant mass content }\end{array}$ & {$[\mathrm{kg}]$} & & & \\
\hline$N$ & Number of plates or turns & N.D. & & & \\
\hline$P$ & Pressure & {$[\mathrm{Pa}]$} & & & \\
\hline param & Parameters & N.D. & & & \\
\hline \multicolumn{6}{|c|}{ Greek characters } \\
\hline$\alpha_{\text {rug }}$ & PHE rugosity factor & $\%$ & $\beta$ & PHE chevron angle & deg \\
\hline$\kappa$ & Polytropic index & N.D. & $\eta$ & Efficiency & N.D. \\
\hline$\lambda_{\mathrm{ev}}$ & $\begin{array}{l}\text { Specific enthalpy of } \\
\text { Vaporization }\end{array}$ & {$\left[\mathrm{Jkg}^{-1}\right]$} & $\rho$ & Density & {$\left[\mathrm{kgm}^{-3}\right]$} \\
\hline$\mu$ & Viscosity & Pas & $\gamma$ & Void fraction factor & N.D. \\
\hline \multicolumn{6}{|c|}{ Subscripts } \\
\hline $1,2,2^{\prime}, 3,4$ & Junction number & & $l$ & Liquid zone & \\
\hline$c$ & Condenser & & $m$ & Mix zone & \\
\hline compr & Compressor & & $\max$ & Maximum & \\
\hline cor & Corrugation & & $\min$ & Minimum & \\
\hline crit & Critical & & motor & Compressor motor & \\
\hline$d$ & Desuperheater & & pass & Number of passes & \\
\hline$e$ & Evaporator & & out & Output of the zone & \\
\hline$e q$ & Equivalent & & $r$ & Refrigerant & \\
\hline $\exp$ & Experiment & & $\operatorname{sim}$ & Simulation & \\
\hline $\exp v$ & Expansion valve & & $s w$ & Swept & \\
\hline fr & Friction & & trans & Transversal & \\
\hline$g$ & Gas zone & & $u c$ & Uncompressible & \\
\hline$h$ & Hydraulic & & $v$ & Volumetric & \\
\hline$i$ & Component index $(\mathrm{d}, \mathrm{c}, \mathrm{e})$ & & $v a c$ & Vacuum & \\
\hline in & Input of the zone & & $z 1, z 2, z 3$ & $\begin{array}{l}\text { First, second or third zone of } \\
\text { heat exchanger }\end{array}$ & \\
\hline is & Isentropic & & & & \\
\hline$j$ & Zone index $(1, \mathrm{~g}, \mathrm{~m})$ & & & & \\
\hline
\end{tabular}




\section{Introduction}

The new monovalent inverter-driven water-to-water heat pump with a desuperheater (compact GSHP with a desuperheater, Blanco et al., in press) can provide the thermal requirements for space heating $(\mathrm{SH})$, cooling and domestic hot water (DHW) for a low energy house in a single unit with high efficiency and a stable output. Nevertheless, there has been only limited research regarding the operation and control of this system. Studies regarding a single frequency GSHP designed for SH that provides DHW by incorporating a desuperheater in its cycle are common in the literature (e.g., Biaou and Bernier, 2008). As no control techniques for frequency or expansion valves have been examined, the results of such studies can be misleading. A better understanding of the compact GSHP with a desuperheater requires a simulation program in which the design, control and evaluation of the system can be performed against changing climate conditions.

However, the refrigeration cycle simulations in the literature, as comprised in Table 1, lack two aspects needed for application to the compact GSHP with a desuperheater. First, they are design-oriented, such that the superheating/subcooling degrees or other performance characteristics are fixed (Hiller and Glicksman, 1976; Stefanuk et al., 1992; Hui and Spitler, 2002; Zhao et al., 2003; Rigola et al., 2005; Winkler et al., 2008; Belman et al., 2009). Therefore, while they can accurately reflect the behavior of the heat pump under ideal conditions, they fail to address the off-design conditions that can occur during the evaluation of the performance of a system throughout an entire year. Second, user-specified initial states of some or all of the thermodynamic variables of the cycle are required as a starting point to solve the algorithm (Hiller and Glicksman, 1976; Fukushima, et al., 1977; Domanski and Didion, 1984; Stefanuk et al., 1992; Koury et al., 2001; Hui and Spitler, 2002; Zhao et al., 2003; Rigola et al., 2005; Winkler et al., 2008; Belman et al., 2009). Because the state of the 
refrigerant is not known, no unique set of initial conditions can be applied to all varying climate and load conditions. When the simulation runs for hundreds of cycles (e.g., to calculate the APF), manually checking the thermodynamic states for each condition becomes an impossible task. The process of identifying an initial condition needs to be transparent to the user.

The objective of this research is the development of a unique simulation for a compact GSHP with a desuperheater. In the presented simulation, a change in paradigm from a designoriented simulation to a performance-oriented simulation is proposed. To address the first issue, the new simulation provides a flexible framework in which no performance parameters are assumed, relying instead on the characteristics of a real installation, namely, the refrigerant charge of the system and the existence of an unknown superheating degree. Additionally, fast adaptive block heat exchanger algorithms are developed to adjust to changing conditions. In this way, realistic subcritical cycles can be fully simulated, even under off-design conditions. Moreover, simulating different operation configurations is possible, such as SH only (mode 1), production of DHW only (mode 2) or for SH and DHW simultaneously (mode 3). The second issue is solved by identifying the solution space of each cycle variable based only on the climate and control inlet conditions to automatically determine a valid initial refrigerant state. Using this method, the simulation can be presented to the user as a black box which can be coupled with a ground heat transfer simulation and/or with a house heat transfer model to obtain a realistic performance estimate for the whole thermal system. This coupling allows the systematic calculation of the Annual Performance Factor (APF), which can be used to evaluate different control schemes.

\section{Simulation development}


Any vapor refrigeration cycle can be described in terms of components and junctions located in between (Richardson, 2006). Fig. 1 depicts the compact GSHP with a desuperheater. The junctions in the component view of Fig. 1(a) represent a unique refrigerant thermodynamic state. The state of these junctions is plotted on the PH diagram, shown in Fig. 1(b). Junction $2^{\prime}$ can exist in either the mix or the gas zones, while junction 3 can exist in the gas, mix or liquid zone, depending on the inlet conditions. Because of the inherent trade-off in computing simulations between speed and detailed dynamic models, only the steady state is considered.

Finding the solution for a refrigeration cycle is subdivided into two subproblems:

- Component modelling algorithms: The output conditions for each component are determined according to its defined specific inlet conditions.

- Cycle convergence algorithm: The operating point of each of the junctions is determined to obtain a balanced solution among all of the components.

Two approaches have traditionally been used for the cycle convergence algorithm. Ding (2007) identifies the simultaneous and sequential solving methods. In this study, a carefully designed initial condition ensures that the sequential module method can be used to achieve convergence for all the study cases. As input, the simulation requires the geometrical information of the heat exchangers, the inlet temperatures and volumetric flow rates of the primary, secondary and DHW streams, and the control variables (expansion valve opening and compressor frequency). All the thermodynamic states of the junctions, the heat transferred at each heat exchanger, the electrical consumption of the compressor and the overall COP can be obtained as output. For each component, the main inlet and outlet variables are listed in Table 2. 
This section will first introduce the assumptions and basic principles that were applied in the development of the simulation. Using these principles, three novel algorithms are introduced: The generic adaptive zone heat exchanger model uses boundary conditions to quickly solve the heat balance inside the heat exchangers for one, two or three refrigerant phases. This model is applied to the desuperheater, condenser and evaporator. The mass flow rate conservation algorithm defines the solution space of each junction in the system according to the inlet climate conditions and calculates the discharge pressure of the compressor based on the control conditions and an initial plausible state. Using the models developed, the global convergence algorithm maintains the heat and mass balance throughout each junction of the cycle. Finally, each component model is presented.

\subsection{Assumptions}

Four important assumptions are made in developing the simulation:

- $\quad$ The model assumes perfect insulation of the system against its surroundings.

- It is assumed that there is no pressure drop in the condenser or desuperheater.

- It is assumed that complete evaporation occurs in the evaporator.

- It is assumed that the pressure change process inside the expansion valve is isenthalpic.

\subsection{Balance and conservation equations}

As heat balance is maintained in every component, the overall system heat balance needs to be guaranteed. The heat extracted from the ground and the compression work should be equal to the heat delivered to the desuperheater and condenser:

$$
Q_{e}+W_{c o m}-Q_{d}-Q_{c}=0
$$


The pressure balance implies that the pressure increase in the compressor must be equal to the pressure decrease in the expansion valve and the pressure drop in the evaporator, as described by Eq. (2):

$$
P_{4}-P_{1}-\Delta P_{e}=0
$$

At the steady state, mass flow regulating devices should provide the same mass flow rate to obtain balance, as shown in Eq. (3):

$$
\dot{m}_{\text {exp }}=\dot{m}_{\text {compr }}
$$

The refrigerant mass content is a property of the system that remains constant at the steady state for any operating condition and any combination of inlet parameters. It has been suggested that when the mass charge is not considered, the simulation results are not from a unique system with different operating conditions, but are instead from many systems with different refrigeration charges (Stefanuk et al., 1992), which is incorrect for the purposes of this simulation. A mass balance implies that at every instant, the sum of the masses of all the components should be equal to the overall refrigerant charge, including the connection piping between components, which is described by Eq. (4):

$$
M_{\text {tube }}=V_{\text {tube }} \rho_{g}\left(P_{2}\right)
$$

The total mass in the system is then obtained using Eq. (5):

$$
M_{\text {compr }}+M_{d}+M_{c}+M_{e}+M_{\text {tube }}=M_{\text {charge }}
$$

\subsection{Generic adaptive zone heat exchanger model}

A novel generic algorithm for a counterflow heat exchanger, in which the geometry, the inlet temperatures and the stream flow rates are known, is presented. The model can successfully 
adapt to different refrigerant zone combinations based on the changing inlet conditions. All of the possible zone combinations presented in Table 3 can be effectively modeled.

The algorithm is presented in Fig. 2. When a heat exchanger is examined, the overall heat transfer coefficients and the zone combinations of the heat exchanger are unknown because they depend on the particular inlet conditions. However, it is possible to monitor the available specific enthalpy change of each zone. To find the zone combination of a particular heat exchanger, a fast and easy solution is to assume initially that there is no phase change inside the heat exchanger, solve the system, and switch to a two or three zone case if the resultant enthalpy change is larger than the available enthalpy. For each zone, an average overall heat transfer coefficient is calculated and the NTU- $\varepsilon$ method is applied. When the heat balance is obtained and the heat transfer area conservation is satisfied, the exchanger is solved, and the refrigerant mass content is calculated.

Solving the problem for one zone can be straightforward, but a change of phase requires solving the problem iteratively to guarantee balance. The developed method maintains the heat balance at every step, while iterating over a boundary variable to satisfy the heat transfer area conservation. The selection of the boundary variable will be addressed later in this section. To reduce the number of iterations, limits on the boundary variable are identified, and an error function based on these limits is constructed such that the initial problem is translated into a one dimensional bounded root searching problem. To solve it, Ridders' method (Ridders, 1979) is selected due to its low computing requirement and short calculation time.

\subsubsection{Heat transfer area conservation and refrigerant mass content calculation}


The available heat transfer area is the sum of the heat transfer area needed for each zone, as described in Eq. (6), where the sub index $i$ is used to denote the appropriate heat exchanger:

$$
A_{i g}+A_{i m}+A_{i l}=A_{i}
$$

After finding a balanced solution for each heat exchanger, the refrigerant mass content must be calculated. The volume of refrigerant in each zone is proportional to the ratio of the heat transfer area for that zone to the total heat transfer area:

$$
V_{i j}=\frac{A_{i j}}{A_{i}} V_{i}
$$

where $j$ represents the zone of consideration. The mass content of the gas or liquid zones is obtained directly from Eq. (8):

$$
M_{i j}=V_{i j} \bar{\rho}_{i j}
$$

To calculate the mass content in the mix zone, the analysis presented by Fukushima et al. (1969) is used, as follows:

$$
M_{i m}=V_{i m} \gamma_{i m} \rho_{i g}\left(1-\gamma_{i m}\right) \rho_{i l}
$$

where $\gamma_{i m}$ is the integral of the void fraction divided by the quality change, as described in Eq. (10):

$$
\gamma_{\text {im }}=\frac{1}{x_{\text {out }}-x_{\text {in }}} \int_{x_{\text {in }}}^{x_{\text {out }}} \frac{x v_{g}}{x v_{g}+(1-x) v_{l}} d x
$$

The total mass content for the heat exchanger is the sum of the mass from each zone, as described in Eq. (11):

$$
M_{i g}+M_{i m}+M_{i l}=M_{i}
$$

\subsubsection{Two zone boundary analysis}

When a single phase change occurs inside the heat exchanger, the temperature of the secondary fluid when the refrigerant is in the saturated state, $T_{i, \text { boundary }}$, is used for iteration. 
For a given $T_{i, \text { boundary }}$, an independent analysis is performed for each zone, starting in the same direction that the refrigerant flows. Initially, $A_{i z l}$ is determined using the NTU- $\varepsilon$ method. The area of the second zone $\left(A_{i z 2}{ }^{l}\right)$ is derived using heat transfer area conservation. Symmetrically, if the heat balance is calculated starting from the second zone, an additional value for the heat transfer area is determined $\left(A_{i z 2}^{2}\right)$. The difference between these two values is defined as an error function, as described in Eq. (12), below:

$$
E_{i}\left(T_{i, \text { oundary }}\right)=A_{i z 2}{ }^{1}-A_{i z 2}{ }^{2}
$$

\subsubsection{Three zone boundary analysis}

For the case with three zones, there exist two boundary temperatures for the secondary stream: one for the saturated vapor and one for the saturated liquid, at constant pressure $P_{2}$. However, these two temperatures are coupled through the heat transfer that occurs in the mix zone, so each can be expressed in terms of the other. As a result, the same methodology described above for two zones can be applied. Assuming condensation direction, $T_{i, \text { boundary }}$ is defined as the boundary temperature of the secondary fluid at the saturated liquid state. The boundary temperature for the saturated gas is then derived based on the enthalpy change that occurs in the mix zone. The gas and mix zone heat transfer areas can be calculated by the NTU- $\varepsilon$ method. Through heat transfer area conservation, $A_{i z 3}{ }^{l}$ is calculated. Applying the heat balance in the third zone produces $A_{i z 3}{ }^{2}$. The error function is then defined in the same way as the case with two zones.

$$
E_{i}\left(T_{i, \text { boundary }}\right)=A_{i z 3}{ }^{1}-A_{i z 3}{ }^{2}
$$

\subsubsection{Mix zone analysis}

In the condenser, when junctions 2 ' and 3 are located inside the mix zone, the average overall heat transfer coefficient changes depending on the condensation mode, which is related to the 
enthalpy change. To find a balanced solution for this case, the exit enthalpy $H_{3}$ is selected as the boundary variable, in which case the same methodology described before can be applied. The error function can then be stated as

$$
E_{c}\left(H_{3}\right)=A_{m}{ }^{1}-A_{c}
$$

where $A_{m}{ }^{1}$ is derived from $H_{3}$ and $A_{c}$ is the total heat transfer area of the heat exchanger, calculated based on geometric considerations.

\subsection{Refrigerant mass flow rate conservation algorithm}

The evaluation of the compressor and expansion valve components should provide an equal mass flow rate at the steady state. The difference between the two models can be defined as:

$$
g\left(\operatorname{param}, P_{1}, T_{1}, P_{2}\right)=\dot{m}_{\text {compr }}-\dot{m}_{\text {exp }}
$$

which is a function of $P_{1}, T_{1}$ and $P_{2}$, assuming $P_{4}=P_{1}+\Delta P_{e}$. Thus, for a fixed point in junction 1 , described by $P_{1}$ and $T_{1}$, the value $P_{2}$ can be obtained such that $\mathrm{g}$ is sufficiently small. To attain plausible junction 1 states, we rely on the application of the second law of thermodynamics to bracket the maximum and minimum values of the following variables:

- $T_{1}, T_{4} \leq T_{e 1}$ : The temperature of the refrigerant at junction 1 or 4 cannot be greater than the inlet temperature from the primary side.

- $T_{3} \geq \max \left(T_{c 3}, T_{d 2}{ }^{\prime}\right)$ : The temperature of the refrigerant at junction 3 cannot be less than the maximum temperature inlet from the secondary side.

- $\quad P_{2} \leq P_{c r i t}$ : The cycle cannot be supercritical

- $\quad P_{1}>P_{v a c}: P_{1}$ must be larger than the vacuum

The described conditions are plotted in the PH diagram shown in Fig. 3(a). The shaded regions represent the solution space for each junction. The limits for $P_{1}, T_{1}$ and $P_{2}$ can then be identified. Moreover, using $g=0$ for a given $T_{1}$, the solution space for $P_{1}$ and $P_{2}$ can be 
further narrowed as shown in the $P_{1}-P_{2}$ plane of Fig. 3(b). By setting limits that are based only on the inlet conditions, not only are the junction states carefully controlled inside the algorithm, but the algorithm also eliminates the need for the user to set an initial refrigerant thermodynamic condition.

From Fig. 3(a), it is observed that junction 1 is completely enclosed by the frontier temperature line $T_{e l}$, the vapor saturation line, and the pressure limits for $P_{l}$. Therefore, for a given $P_{1}$ and $T_{1}$ inside this region, finding $P_{2}$ is reduced to a single dimension root finding problem. Ridders' method is then applied.

\subsection{Global convergence algorithm}

The global convergence algorithm developed is composed of two core methods. The first method iterates through all the components of the cycle from an initial to a final state of junction 1, solving for each component. Successive substitution is used to resolve the pressure drop in the evaporator. The second method determines the error between the initial and final states of junction 1 and calculates the next iteration state to find convergence. In this case there are more than one boundary variables, so an analogy with the root finding method has to be developed. The multivariable global error function eval is defined in Eq. (16), in which $T_{1}, T_{1}{ }^{\prime}, H_{1}$ and $H_{1}{ }^{\prime}$ are respectively the initial and final temperatures and enthalpies of junction 1; and $M_{\text {charge }}$ and $M_{\text {charge }}$ are the difference between the system's refrigerant charge and the calculated charge, respectively:

$$
\text { eval }=\sqrt{\left(\frac{T_{1}-T_{1}{ }^{\prime}}{T_{1 \max }-T_{1 \text { min }}}\right)^{2}+\left(\frac{H_{1}-H_{1}{ }^{\prime}}{\lambda_{e v}}\right)^{2}+\left(\frac{M_{\text {charge }}-M_{\text {charge }}{ }^{\prime}}{M_{\text {chargemax }}}\right)^{2}}
$$

Convergence is translated into a multi-dimension minimization problem, in which the final solution is obtained for the enthalpy $H_{1}$ and the temperature $T_{1}$ that reduces the error function 
below the desired resolution, while maintaining the appropriate balance. For the present simulation, the bounded Nelder-Mead method is selected according to Luersen et al. (2004) because other techniques require calculating the first-order derivate and the Hessian of eval at every step, which can be costly in terms of computing power. Additionally, at every step the solution is within the boundary limits, contrary to other techniques, in which iterations can reach prohibited spaces, such as in the Newton-Raphson method. To commence the algorithm, an initial simplex is constructed as the geometrical center point of the solution space of junction 1. The complete algorithm is described in Fig. 4.

\subsection{Component modeling}

\subsubsection{Compressor}

A model for the rotary type compressor with variable speed is developed. The inlet state of the refrigerant, the discharge pressure and geometrical parameters are taken as input. The model then calculates the mass flow rate $\dot{m}_{c o m p r}$, the enthalpy of the discharged refrigerant $\mathrm{H}_{2}$ and the compressor electric power $W_{e l}$. The mass flow rate is determined from the compressor frequency and the swept volume as described in Eq. (17):

$$
\dot{m}_{\text {compr }}=\eta_{v} \rho_{1} V_{s w} \text { freq }
$$

where $\eta_{v}$ is the volumetric efficiency described by Eq. (18):

$$
\eta_{v}=1+\frac{V_{u c}}{V_{s w}}-\frac{V_{u c}}{V_{s w}}\left(\frac{P_{2}}{P_{1}}\right)^{\kappa}
$$

Here, the adiabatic index is calculated from junction 1 . The electrical power consumption is described by Eq. (19):

$$
W_{e l}=\frac{W_{c o m}}{\eta_{\text {motor }}}
$$


where the motor loss efficiency $\eta_{\text {motor }}$ is evaluated according to Chen et al. (2002) from Eq. (20):

$$
\eta_{\text {motor }}=A_{0}+A_{1} \text { freq }+A_{2} W_{i s}+A_{3} \ln \left(\frac{P_{2}}{P_{1}}\right)+A_{4} W_{i s} \ln \left(\frac{P_{2}}{P_{1}}\right)
$$

where $W_{i s}$ is the isentropic work, calculated using Eq. (21):

$$
W_{i s}=\dot{m}_{c o m p r} \frac{\kappa}{\kappa-1} \frac{P_{1}}{\rho_{1}}\left[\left(\frac{P_{2}}{P_{1}}\right)^{\frac{\kappa-1}{\kappa}}-1\right]
$$

The actual compression process is related to the ideal process by the friction efficiency. For the present study, the friction efficiency is considered constant. Eq. (22) is then used to derive the compression work:

$$
W_{c o m}=\frac{W_{i s}}{\eta_{f r}}
$$

The discharge enthalpy of the refrigerant can then be determined from the compression work, as described by Eq. (23):

$$
H_{2}=H_{1}+\frac{W_{c o m}}{\dot{m}}
$$

The refrigerant mass content in the compressor is calculated from the swept volume at the average density of the refrigerant through the compression process, as shown in Eq. (24):

$$
M_{\text {compr }}=V_{s w} \bar{\rho}_{12}
$$

where $\bar{\rho}_{12}$ refers to the arithmetic mean density between junctions 2 and 1 .

\subsubsection{Desuperheater}

The desuperheater model is based on a horizontal, double-tube, coil-type heat exchanger, as shown in Fig. 5(a). While the refrigerant inlet (junction 2) is always in the gas zone, the zone for the exit of the refrigerant (junction 2') varies. Applying the generic heat exchanger model 
yields two cases, as follows: (case DGG) when the exit of the heat exchanger is still in the gas phase and (case DGM) when the exit has started condensing. The overall heat transfer coefficient is calculated for each zone based on the specific geometrical characteristics and heat transfer correlations, and it is included in Appendix A.

For the DGG case, the solution is obtained directly by applying the NTU- $\varepsilon$ method. The DGM case is solved by applying the generic heat exchanger model for two zones. The conservation of the heat transfer area is maintained by setting $A_{d l}=0$ in Eq. (6). To apply Ridders' method, the boundary temperature $T_{d \sigma}$ is selected for iteration. The $T_{d \sigma}$ limits are calculated using Eqs. (25) and (26). The error function is defined, as stated in Eq. (12), for $i=$ $d$ and $z 2=m$.

$$
\begin{gathered}
T_{d 6}{ }^{\max }=\min \left(T_{2}-\frac{Q_{d g}}{\min \left(C_{p w} \dot{m}_{w}, C_{p g} \dot{m}\right)}, T_{6}\right) \\
T_{d 6}{ }^{\min }=T_{d 2}{ }^{\prime}
\end{gathered}
$$

\subsubsection{Condenser}

The condenser and evaporator are modeled as brazed plate type, single pass, and water to water heat exchangers, as shown in Fig. 5(b). Depending on the heat transfer in the desuperheater, junction 2' can be either in the gas or mix zone. Similarly, junction 3 can be in the gas, mix or liquid zone, depending on the heat transfer in the condenser. The combination of these inlet-outlet relationships results in five cases: CGG, CGM, CGL, CMM, and CML.

The CGG case is solved by direct application of the NTU- $\varepsilon$ method. The generic heat exchanger model is applied to solve the CGM case, where $T_{c 6}$ represents the boundary 
temperature. The limits are found using Eqs. (27) and (28). The error function is obtained by setting $i=c$ and $z 2=m$ in Eq. (12).

$$
\begin{gathered}
T_{c 6}{ }^{\max }=\min \left(T_{2}{ }^{\prime}-\frac{Q_{c g}}{\min \left(C_{p c} \dot{m}_{c}, C_{p g} \dot{m}\right)}, T_{6}\right) \\
T_{c 6}{ }^{\text {min }}=T_{c 3}
\end{gathered}
$$

To apply the generic heat exchanger algorithm to the three zone case for CGL, the limits of the boundary temperature $T_{c 7}$ are determined using Eqs. (29) and (30). From Eq. (13), the error function is determined with $i=c$ and $z 3=l$.

$$
\begin{gathered}
T_{c 7}{ }^{\max }=\min \left(T_{2}{ }^{\prime}-\frac{Q_{c g}}{\min \left(C_{p c} \dot{m}, C_{p g} \dot{m}\right)}-\frac{Q_{c m}}{C_{p c} \dot{m}}, T_{6}-\frac{Q_{c m}}{C_{p c} \dot{m}}, T_{c 3}+\frac{Q_{c l}{ }^{\max }}{C_{p c} \dot{m}}, T_{7}\right) \\
T_{c 7}{ }^{\min }=T_{c 3}
\end{gathered}
$$

The CMM case is solved based on the mix zone analysis from subsection 2.3.4. The limits on $H_{3}$ are shown in Eqs. (31) and (32). The error function is described by Eq. (14).

$$
\begin{gathered}
H_{3}{ }^{\max }=H_{2}{ }^{\prime} \\
H_{3}{ }^{\min }=H_{7}
\end{gathered}
$$

The CML case is solved in the same way as the CGM case. The limits of the boundary temperature $T_{c 7}$ are obtained from Eqs. (33) and (34). The error is determined using Eq. (12), where $i=c$ and $z 2=l$.

$$
\begin{gathered}
T_{c 7}{ }^{\max }=\min \left(T_{2^{\prime}}-\frac{Q_{c m}}{C_{p c} \dot{m}}, T_{c 3}+\frac{Q_{c l}{ }^{\max }}{C_{p c} \dot{m}}, T_{7}\right) \\
T_{c 7}{ }^{\min }=T_{c 3}
\end{gathered}
$$

\subsubsection{Expansion valve}


The electronic expansion valve is modeled based on the pressure drop across an orifice. The Chuan et al. (2006) modified model is used. Eq. (35) shows the resulting mass flow rate with controlled steps:

$$
\dot{m}_{\text {exp }}=\eta_{\text {exp }} \rho_{3 l}\left[B_{0}\left(\frac{\text { step }}{A_{\max }}\right)^{2}+B_{1}\left(\frac{\text { step }}{A_{\max }}\right)\right] \sqrt{B_{2}\left(\frac{P_{2}-P_{4}}{\rho_{3 l}}\right)}
$$

where $A_{\max }$ represents the maximum opening of the expansion valve. Because the expansion valve is modeled as an orifice, it is assumed that the valve contains no refrigerant mass.

\subsubsection{Evaporator}

The enthalpy of junction 4 is the same as junction 3 but at pressure $P_{4}$ and is in the mix zone. The exit of the evaporator (junction 1) is assumed to be in the gas zone, resulting in case EMG. To solve this case, the limits of the boundary temperature $T_{e 5}$ are obtained from Eqs. (36) and (37). Eq. (12) is used to determine the error where $i=e$ and $z 2=g$.

$$
\begin{gathered}
T_{e 5}{ }^{\max }=T_{e 1} \\
T_{e 5}{ }^{\min }=\max \left(T_{e 1}-\frac{Q_{e g}{ }^{\max }}{C_{p e} \dot{m}}, T_{4}+\frac{Q_{e m}}{C_{p e} \dot{m}}, T_{5}\right)
\end{gathered}
$$

The experimental results reveal that while the condensing pressure drop can be on the order

of $10^{1} \mathrm{~Pa}$, the evaporator pressure drop can be on the order of $10^{3} \mathrm{~Pa}$, therefore it is considered. The pressure drop is calculated based on the work by Han et al. (2003).

\section{Experimental Setup}

Simulation results were compared with experiments conducted on a prototype compact GSHP with a coil type desuperheater developed by Sunpot Co. Ltd. The compact GSHP uses refrigerant R410A with a nominal charge of $1.8 \mathrm{~kg}$. The prototype was coupled with a test 
station developed by the authors, which can be used to examine the performance of any water-to-water heat pump. All the components and connection pipes were tightly covered with EPT/EPDM insulation with an R-value of 4.1. Analysis on the pipes revealed a maximum heat loss for water of $18.21 \mathrm{Wm}^{-1}$. Ambient temperature was maintained between 20 and $24^{\circ} \mathrm{C}$ throughout the experiments. The examined conditions are shown in Table 4. Detailed information is found in (Blanco et al., in press). 118 experimental results of the system operating in mode 3 were extracted for this study.

\section{Results and discussion}

\subsection{System simulation results}

To examine the precision of the developed simulation, it was executed for the same inlet conditions as the experimental data. The heat transfer of each heat exchanger, $W_{e l}$ and the COP calculated as the ratio of the total heating output to the compressor's electrical input, were compared. The results are shown in Fig. 6. $W_{e l}$ has a maximum deviation with the experimental results of less than $10 \%$. For $Q_{d}$, only $6.78 \%$ of the data has a total deviation greater than $15 \%$. For $Q_{c}$ and $Q_{e}$, the deviations are $7.62 \%$ and $12.7 \%$, respectively. Examining the COP, only $4.23 \%$ of the results show a difference greater than $15 \%$ compared to the experimental data. Consequently, the simulation exhibits good agreement with the experimental results. However, the previous analysis is not sufficient to show the versatility of the simulation. The equation fitted models show equivalent results to the experimental work. However, they cannot describe the thermodynamic states of each junction in the cycle. The developed simulation has this capability, as shown in the next subsection.

\subsection{Simulated refrigeration cycles}


Fig. 7 shows two PH diagram comparisons between experimental and simulated results for various inlet conditions. It can be seen that the simulation successfully fits the changing climate and control conditions. The numerical comparison of the junctions is presented in Table 5, and the highest relative error, calculated using Eq. (38), is less than $3 \%$ for all the junctions:

$$
\text { relative error } \%=\sqrt{\left(\frac{H_{\exp }-H_{\text {sim }}}{H_{\exp }}\right)^{2}+\left(\frac{P_{\exp }-P_{\text {sim }}}{P_{\exp }}\right)^{2}}
$$

It has been shown that the model can predict well the refrigeration cycles in the PH diagram. However, to provide further clarity, a systematic performance analysis regarding changing climate conditions is presented.

\subsection{Mapping results}

The maximum COP and total heat transfer for the set of evaluated climate and control conditions are compared with the experimental results in the maps shown in Fig. 8 with $T_{d 2}{ }^{\prime}=$ 5 and $17^{\circ} \mathrm{C}$. This figure is extremely important not only for showing the maximum COP that can be achieved for each frequency at a given ground inlet temperature based on the target $T_{c 2}{ }^{\prime}$ and $T_{d 2}$, but it also indicates the wide range of climate conditions the simulation can correctly predict. In fact, the maximum deviation with experimental results was $8.78 \%$ for the COP and $11.61 \%$ for the total heat transfer.

\subsection{Application of the simulation to various operation modes}

After demonstrating the robustness of the simulation against changing conditions and strong precision with respect to experimental results, a unique feature is presented. So far, only one operation mode has been investigated, in which DHW is produced together with $\mathrm{SH}$. Nevertheless, the real operation of the system requires the ability to handle other operation 
modes. Fig. 9 shows the operation of the system for modes 1, 2 and 3. While the cycles of mode 1 and 3 do not substantially change, the condensation pressure in mode 2 is much higher than in the other two modes. This characteristic behavior of the GSHP with a desuperheater can be exploited using this unique simulation for control analysis, according to the set operation mode.

\subsection{Superheating degree control}

Fig. 10 shows the variation of the COP according to the change in the opening of the expansion valve. For mode 1 in Fig. 10(a), the highest COP occurred with a superheating degree of $8.1^{\circ} \mathrm{C}$, while for mode 3 in Fig. $10(\mathrm{~b})$, the highest COP occurred with a superheating degree of $9.8^{\circ} \mathrm{C}$. In mode 3 it is important to note that for higher expansion valve steps, the refrigerant temperature at the compressor outlet is lower than the DHW objective temperature, therefore cannot be considered. For the same system and refrigerant charge, the highest COP occurs at different values, suggesting that setting a fixed superheating degree may not necessarily be the best strategy for maximizing the COP.

\section{Conclusions}

An original vapor refrigerant cycle simulation was constructed for a compact GSHP with a desuperheater based only on the refrigerant charge, the physical parameters of the components and the control parameters. An analysis of the boundary conditions was performed to define the solution space in which the states of the junctions of the system are located. Using a sequential component solving algorithm and adaptive zone models for the heat exchangers, global convergence was achieved using multidimensional error minimization techniques. The simulation is capable of predicting space heating or cooling capacities, domestic hot water generation heat transfer and compressor power. Furthermore, 
the simulation successfully models different operation modes of the system, such as space heating only, domestic hot water only, and a combination of the two.

A prototype GSHP with a desuperheater was constructed, and experiments were conducted. Comparing the experimental data, which covered extensive climate conditions, the simulation results showed that for the COP, only $4.23 \%$ of the results have a deviation greater than $15 \%$ (showing the range of application and the precision of the simulation).

Using the simulation, it was shown that the highest COP for space heating only mode and combined space heating and domestic hot water production, occur at different superheating degrees, suggesting that a constant superheating degree strategy may not provide the highest COP for all operating conditions.

Finally, a complete mapping of the maximum COP and the total heat transfer occurring under the tested climate conditions was performed to compare the simulated and experimental results. This comparison showed a maximum deviation of $8.78 \%$ for the COP and $11.61 \%$ for the total heat transfer. The results indicate that the simulation can be used to test different control techniques and parameter variations to increase the overall system $\mathrm{COP}$ and to simulate off-design conditions.

\section{Acknowledgements}

The authors would like to thank Mr. Niki, Mr. Okamoto and Mr. Uchino from Sunpot Co. Ltd. for their insight into the prototype machine. In addition, we would like to thank Mr. Nakamura from Hokkaido University for his help with the development of the experiments, and we thank Ph.D. Katsura and Mr. Umezawa, formerly from Hokkaido University, for their 
fruitful discussions. The financial support from the Ministry of Education, Culture, Sports, Science and Technology of Japan is also greatly appreciated.

\section{Appendix A. Area calculation and heat transfer correlations for heat exchanger heat}

\section{transfer}

\section{A.1 Desuperheater}

The overall heat transfer coefficient is determined based on the geometrical parameters and the mass flow rates of the refrigerant and water streams. The total heat transfer area is calculated using Eq. (A.1-1):

$$
A_{d}=N_{d} \sqrt{\pi D_{d}^{2}+P i^{2}}\left(w t_{d}+c\right)
$$

where $c=3^{-1} \pi d_{d}$ represents the contact surface between the hot and cold tubes of the desuperheater. The equivalent diameter for the tubes is calculated using Eq. (A.1-2):

$$
d_{h}=\frac{4}{2 \cdot w t_{d}+\pi \cdot d_{d}}\left[d_{d} \cdot w t_{d}+\left(\frac{\pi \cdot d_{d}^{2}}{4}\right)\right]
$$

The transversal area is calculated using Eq. (A.1-3), and the total volume is determined using Eq. (A.1-4). To derive the overall convective heat transfer, it is necessary to determine the average bulk velocity for each of the fluids, as described in Eq. (A.1-5):

$$
\begin{gathered}
A_{d \text { trans }}=\frac{\pi \cdot d_{d}^{2}}{4}+w t_{d} \cdot d_{d} \\
V_{d}=A_{d \text { trans }} N_{d} \sqrt{\pi D_{d}^{2}+P i^{2}} \\
v e l_{d}=\frac{\dot{m}}{\rho_{d} A_{d \text { trans }}}
\end{gathered}
$$

Using these velocities and the refrigerant and water properties, the Reynolds and Prandtl numbers can be derived. Using the hydraulic diameter, the friction factor for the tubes can be calculated according to Haaland (1983). The Nusselt number for a single phase in straight 
tubes is calculated according to Gnielinski (1976). This correlation is used for single phase streams. Additionally, the coil heat transfer enhancement proposed by Schmidt (1967) is used. The convective heat transfer coefficient can then be derived for each stream.

In the mix zone, the correlation provided by Shah (1981) is applied. For the liquid state, Gnielinksi's correlation with curvature for the refrigerant at the same pressure in the saturated liquid state is used. From the respective convective heat transfer coefficient for both streams, the overall heat transfer coefficient can be derived for each zone.

\section{A.2 Condenser and evaporator}

Because the condenser and evaporator heat exchangers are identical, the heat transfer area for each can be determined using Eq. (A.2-1):

$$
A_{i}=\left(N_{i}-2\right) h t_{i} w t_{i} \alpha_{r u g}
$$

The transversal channel area is described by Eq. (A.2-2), and the total volume of the heat exchanger is described by Eq. (A.2-3):

$$
\begin{aligned}
& A_{\text {itrans }}=w t_{i}\left(\frac{L_{i}-N_{i} t h_{i}}{N_{i}-2}\right) \\
& V_{i}=w t_{i}\left(\frac{L_{i}-N_{i} t h_{i}}{2}\right) h t_{i}
\end{aligned}
$$

The equivalent hydraulic diameter is determined using Eq. (A.2-4):

$$
d_{i h}=\frac{2 A_{i t r a n s}}{w t_{i}+\frac{A_{\text {itrans }}}{w t_{i}}}
$$

Gnielinski's correlation is used for both streams when there is no change of phase. For the condensation zone, the correlation provided by Shah is applied. For evaporation, the method proposed by Kandlikar (1990) is applied. The overall heat transfer coefficient can therefore be calculated for each zone. 


\section{References}

Belman, J. M., Navarro-Esbrí, J., Ginestar, D., Milian, V., 2009. Steady-state model of a variable speed vapor compression system using R134A as working fluid. Int. J. Energy Res. 34(11), 933-945.

Biaou, A. L., Bernier, M. A., 2008. Achieving total domestic hot water production with renewable energy. Build. Environ. 43, 651-660.

Blanco, D.L., Nagano, K., Morimoto, M., in press. Experimental study on a monovalent inverter-driven water-to-water heat pump with a desuperheater for low energy houses, Appl. Therm. Eng., doi: 10.1016/j.applthermaleng.2012.07.008.

Chen, Y., Halm, N. P., Braun, J. E., Groll, E. A., 2002. Mathematical modeling of scrolls compressors-part II: Overall scroll compressor modeling. Int. J. Refrigeration 25, 751-764.

Chuan, Z., Shanwei, M., Jiangpin, C., Zhijiu, C., 2006. Experimental analysis of R22 and R407C flow through electronic expansion valves. Energy Convers. Manage. 47, 529-544.

Ding, G., 2007. Recent developments in simulation techniques for vapour-compression refrigeration systems. Int. J. Refrigeration 30, 1119-1133.

Domanski, P., Didion, D. 1984, Mathematical model of an air-to-air heat pump equipped with a capillary tube. Int. J. Refrigeration 7(4), 249-255. 
Fukushima, T., Arai, A., Arai, N., 1977. Simulation of refrigeration cycle for air conditioners. JSRAE Reito 52 (593), 301-314.

Gnielinski, V., 1976. New equations for heat and mass transfer in turbulent pipe and channel flow. Int. Chem. Eng., 16, 359-368.

Haaland, S. E., 1983. Simple and explicit formulas for the friction factor in turbulent pipe flow. J. Fluids Eng. 105, 89-90.

Han, D.H., Lee, K.J., Kim, Y.H., 2003. Experiments on the characteristics of evaporation of R410A in brazed plate heat exchangers with different geometric configurations. Appl. Therm. Eng. 23, 1209-1225.

Hiller, C. C., Glicksman, L. R., 1976. Improving heat pump performance via compressor capacity control - analysis and test. Technical report, Massachusetts Institute of Technology.

Hui Jin, Spitler, J.D., 2002. A parameter estimation based model of water-to-water heat pumps for use in energy calculation programs. ASHRAE Transactions 108 (1), 3-17

Kandlikar, S., 1990. A general correlation for saturated two-phase flow boiling heat transfer inside horizontal and vertical tubes. J. Heat Transfer 112, 219-228.

Koury, R.N.N., Machado, L., Ismail, K.A.R., 2001. Numerical simulation of a variable speed refrigeration system. . Int. J. Refrigeration 24, 192-200. 
Luersen, M., Le Riche, R., Guyon, F. 2004, A constrained, globalized, and bounded Nelder Mead method for engineering optimization, Struct. Multidiscip. O. 27, 43-54.

Richardson, D., 2006. An object oriented simulation framework for steady-state analysis of vapor compression refrigeration systems and components. Ph.D. thesis dissertation, University of Maryland.

Ridders, C., 1979. A new algorithm for computing a single root of a real continuous function. Trans. Circuits Syst. Vol. CAS-26 (11), 979-980.

Rigola, J., Raush, G., Pérez-Segarra, C.D., Oliva, A., 2005. Numerical simulation and experimental validation of vapor compression refrigeration systems. Special emphasis on $\mathrm{CO}_{2}$ trans-critical cycles. Int. J. Refrigeration 28, 1225-1237

Schmidt, E. 1967, Wärmeübergang und druckverlust in rohrschlangen, Chem. Ing. Tech. 39(13), 781-789.

Shah, M. M. 1981, Heat transfer during film condensation in tubes and annuli; a literature survey. ASHRAE Transactions 87 (1), 1086-1105.

Stefanuk, N. M., Aplevich, J. D., Renksizbulut, M., 1992. Modeling and simulation of a Superheat-controlled water-to-water heat pump. ASHRAE Transactions 98(2), 172-184.

Winkler, J1., Aute, V., Radermacher, R., 2008. Comprehensive investigation of numerical methods in simulating a steady-state vapor compression system. Int. J. Refrigeration 31, 930- 
942.

Zhao, P.C., Ding, G.L., Zhang, L., Zhao, L., 2003. Simulation of a geothermal heat pump with non-azeotropic mixture, Appl. Therm. Eng. 23, 1515-1524. 


\section{LIST OF FIGURES}

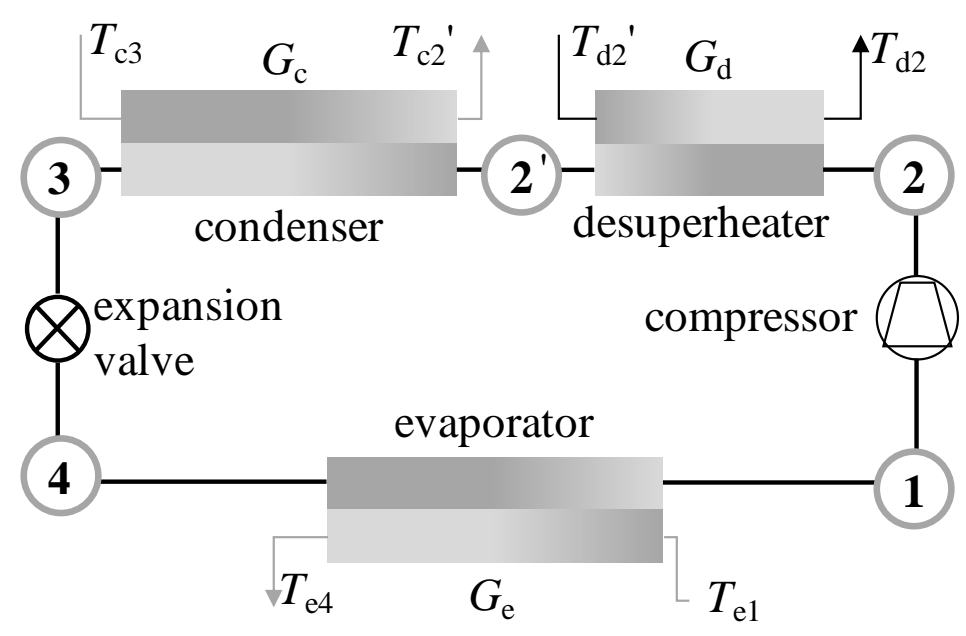

a) Component diagram

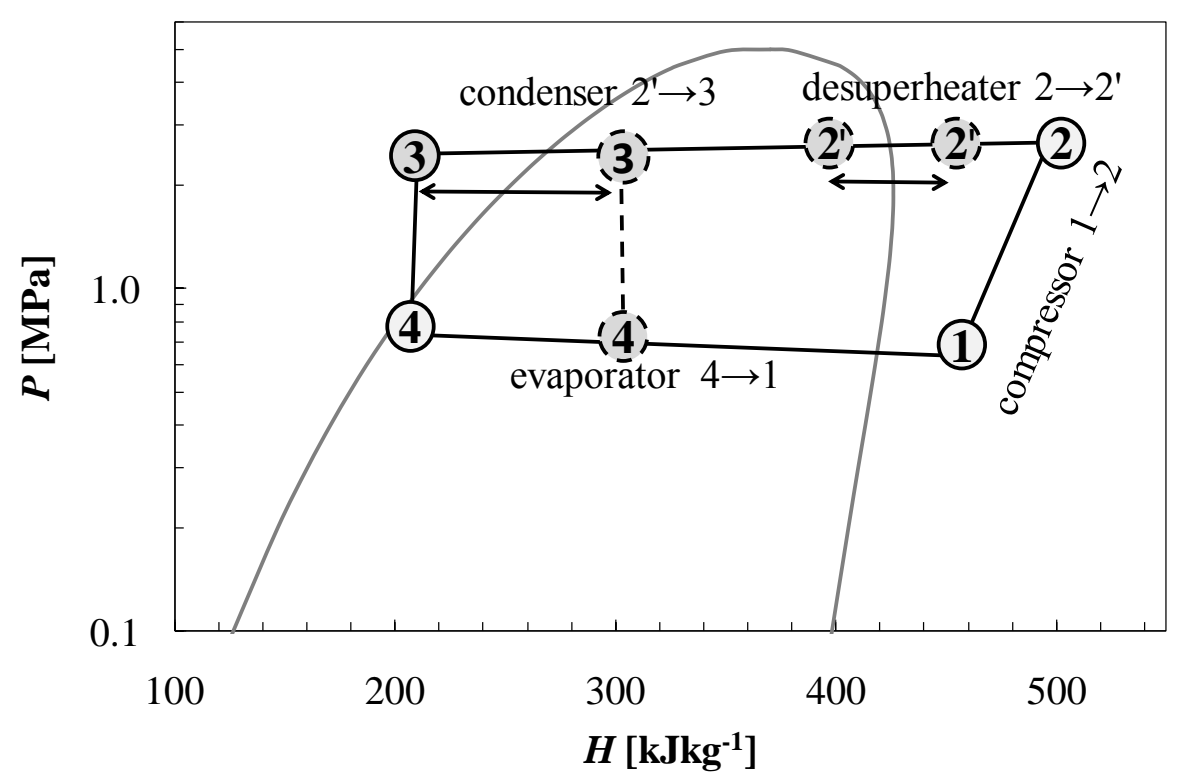

b) Representation in the PH diagram

Fig. 1. Compact GSHP with desuperheater 


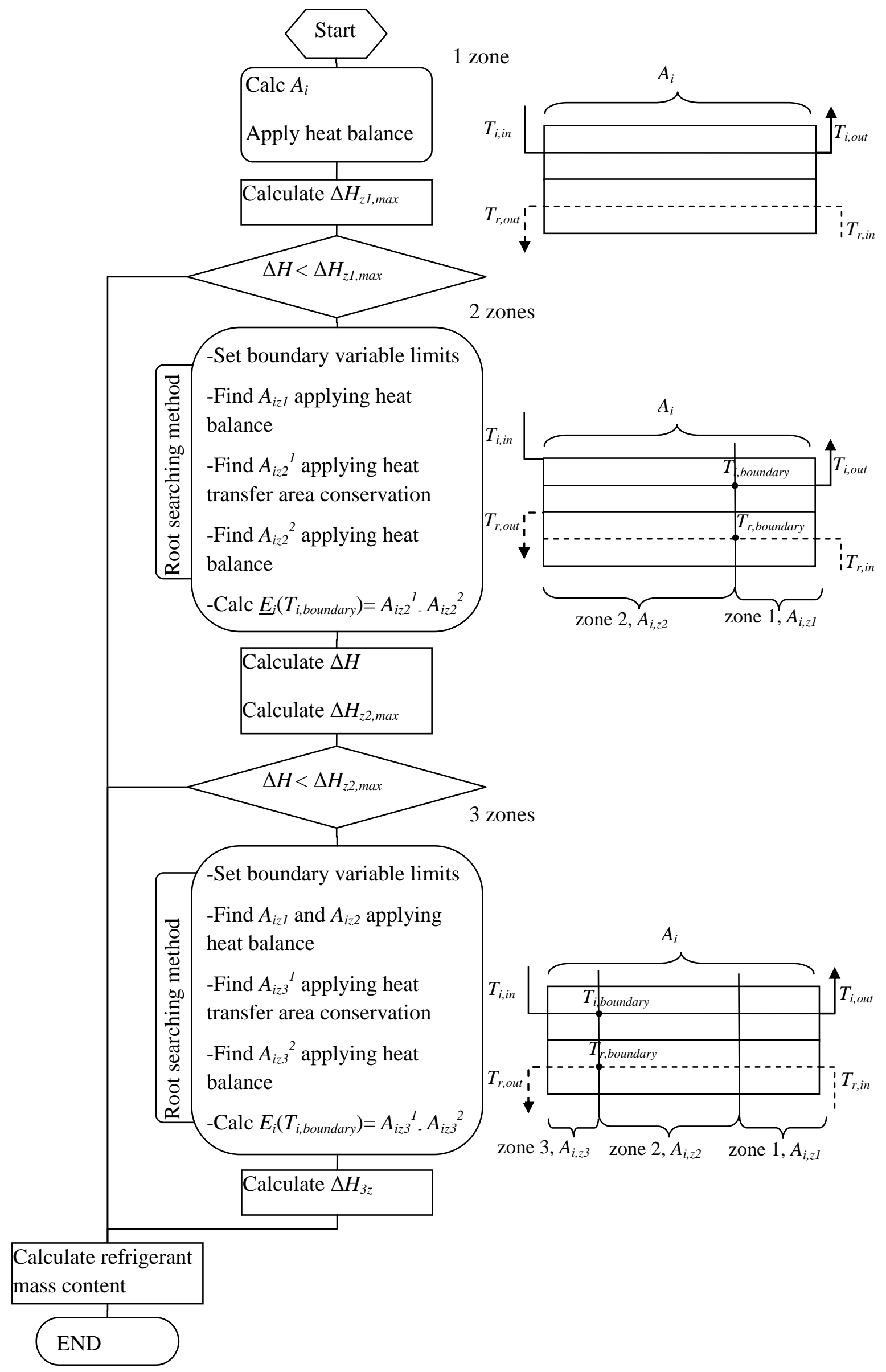

Fig. 2. Generic adaptive zone heat exchanger model 


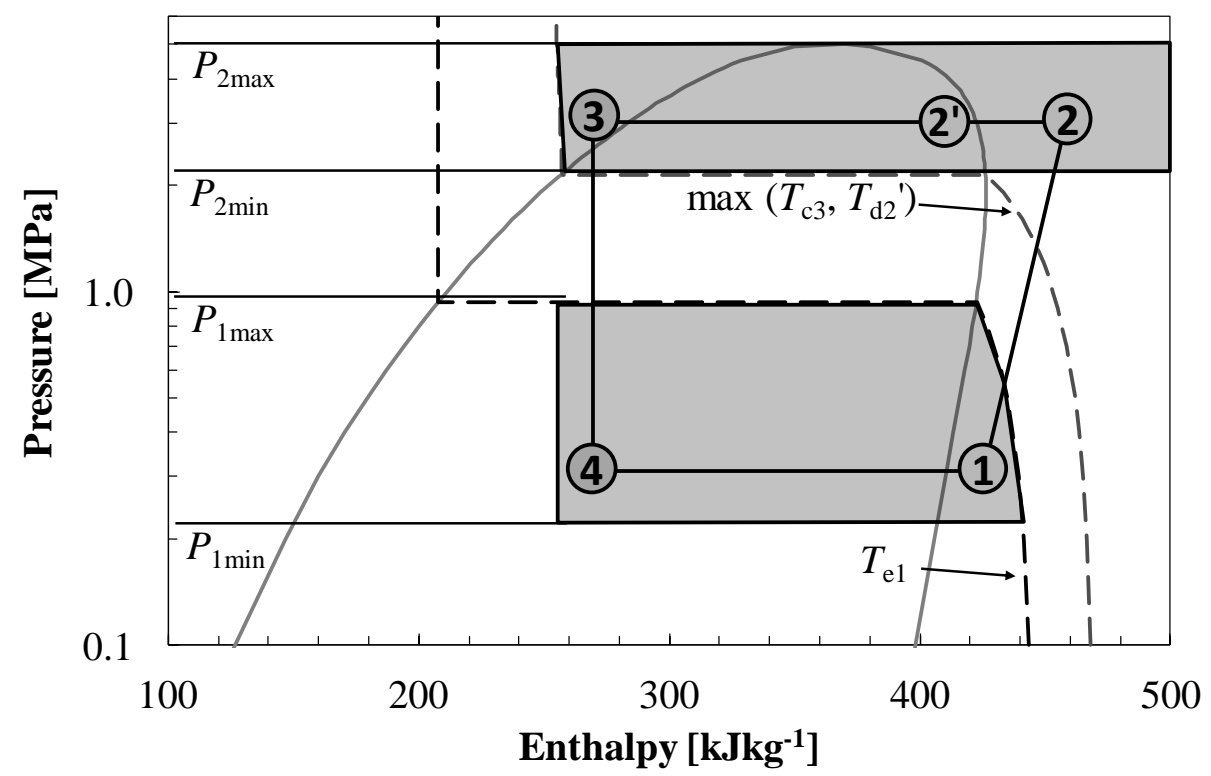

a) Solution space for the cycle junctions based on inlet conditions

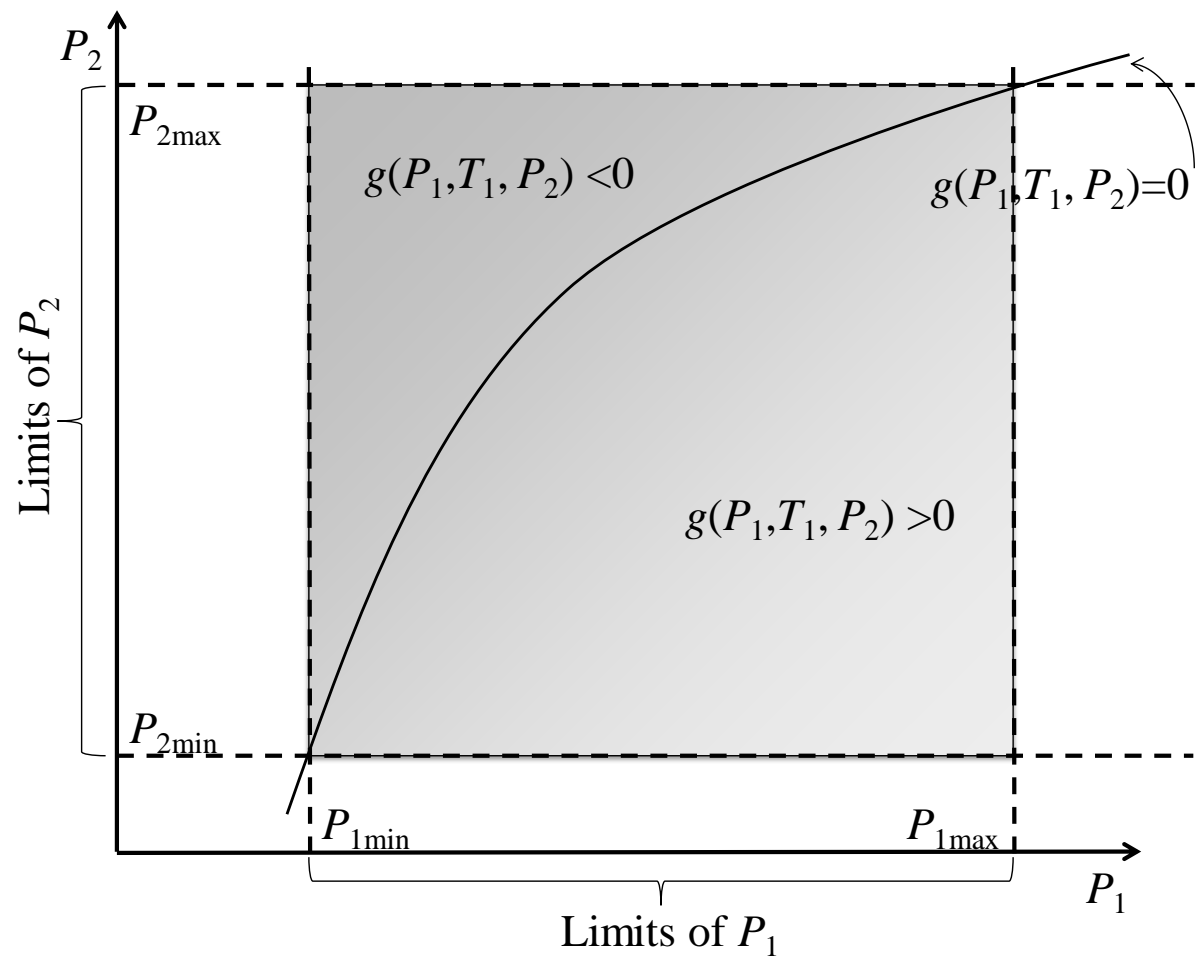

b) The limits for the suction pressure $P_{1}$ are set according to the limits of the discharge pressure $P_{2}$. The function $g$ expresses the difference between the mass flow rate calculated by each regulation device in the cycle. The solution for $P_{1}, T_{1}$, and $P_{2}$ represents a point that must exist on the line $\mathrm{g}$ within the shaded region

Fig. 3. Solution space for each junction based on the refrigerant mass flow rate conservation algorithm 


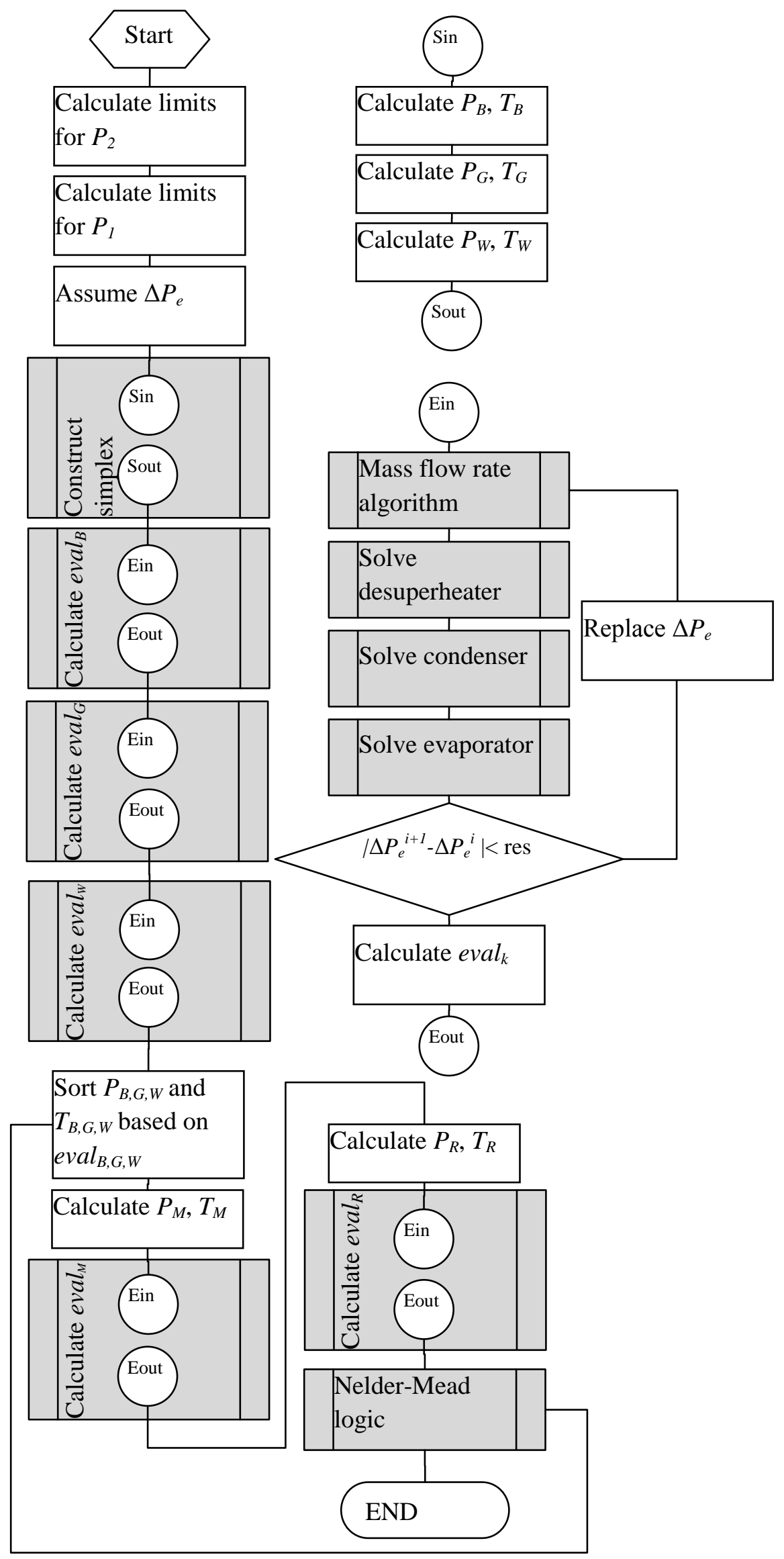

Fig. 4. Global convergence algorithm 


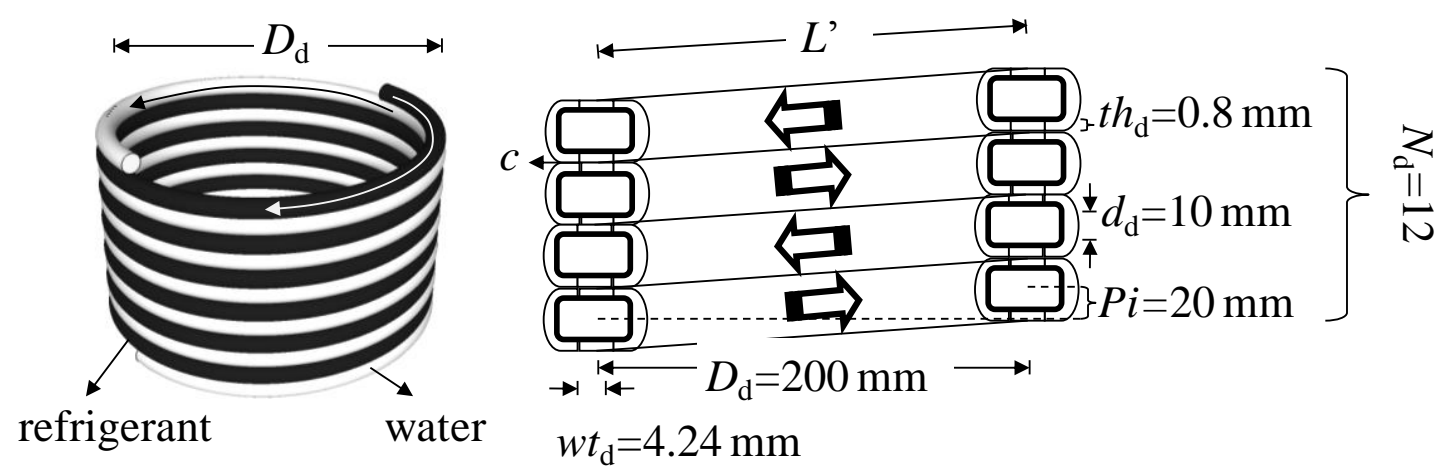

a). Indirect contact coil type desuperheater

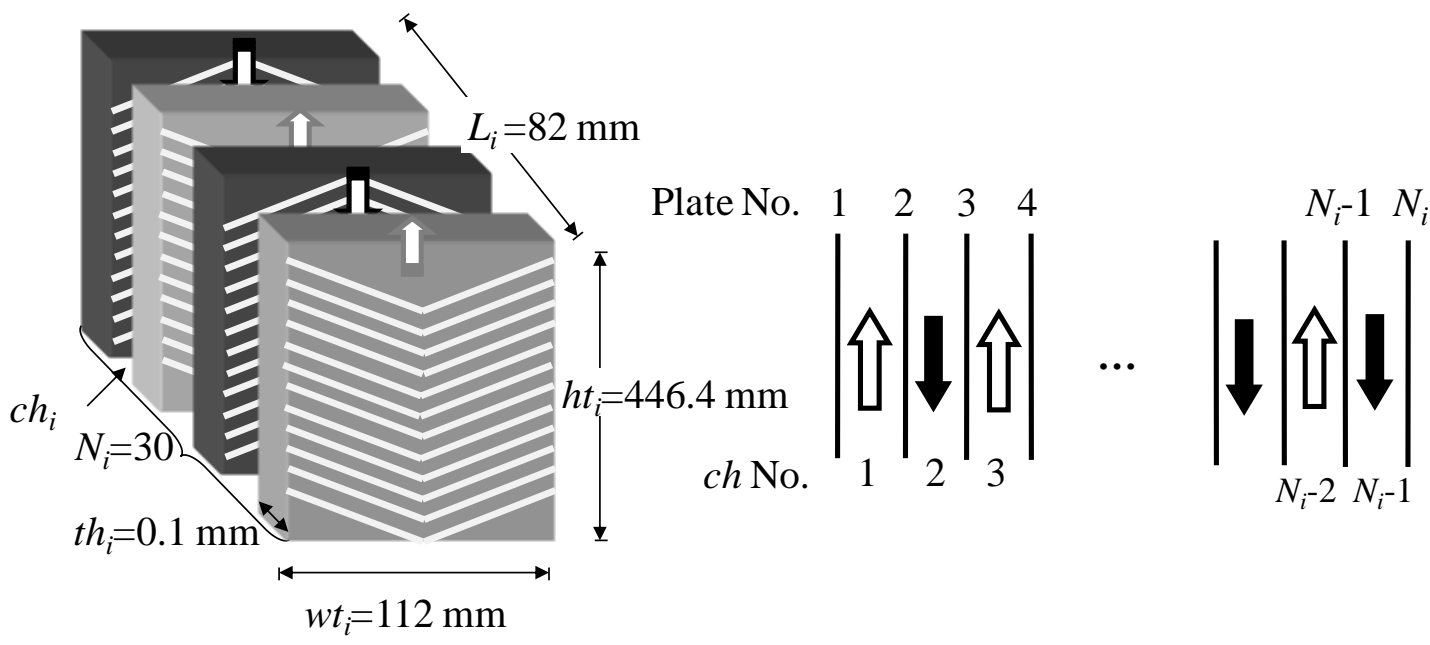

b) Condenser and evaporator plate type heat exchangers

Fig. 5. Geometrical parameters of the heat exchanger components of the prototype 

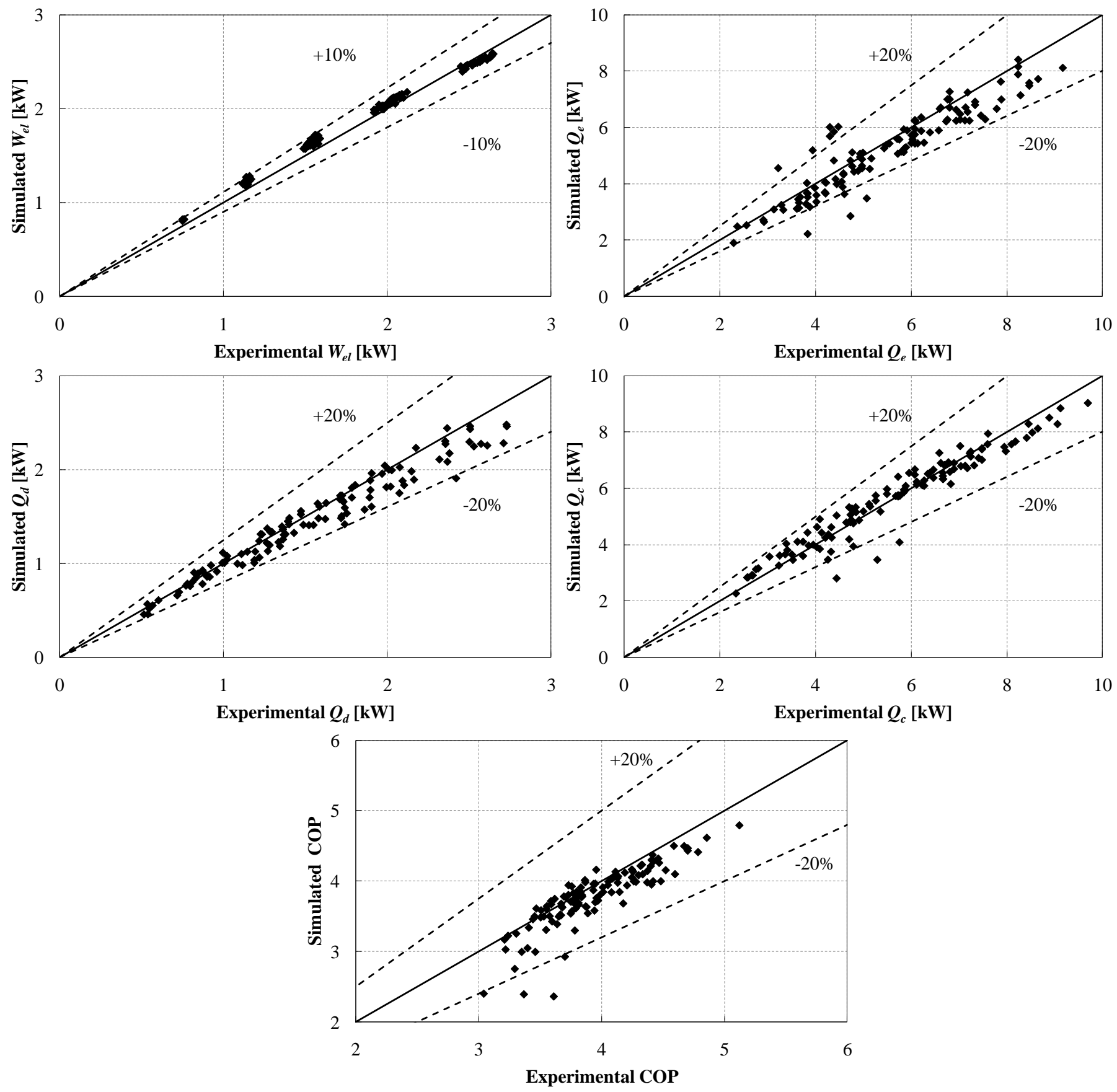

Fig. 6. Complete system comparison between experimental and simulation results 

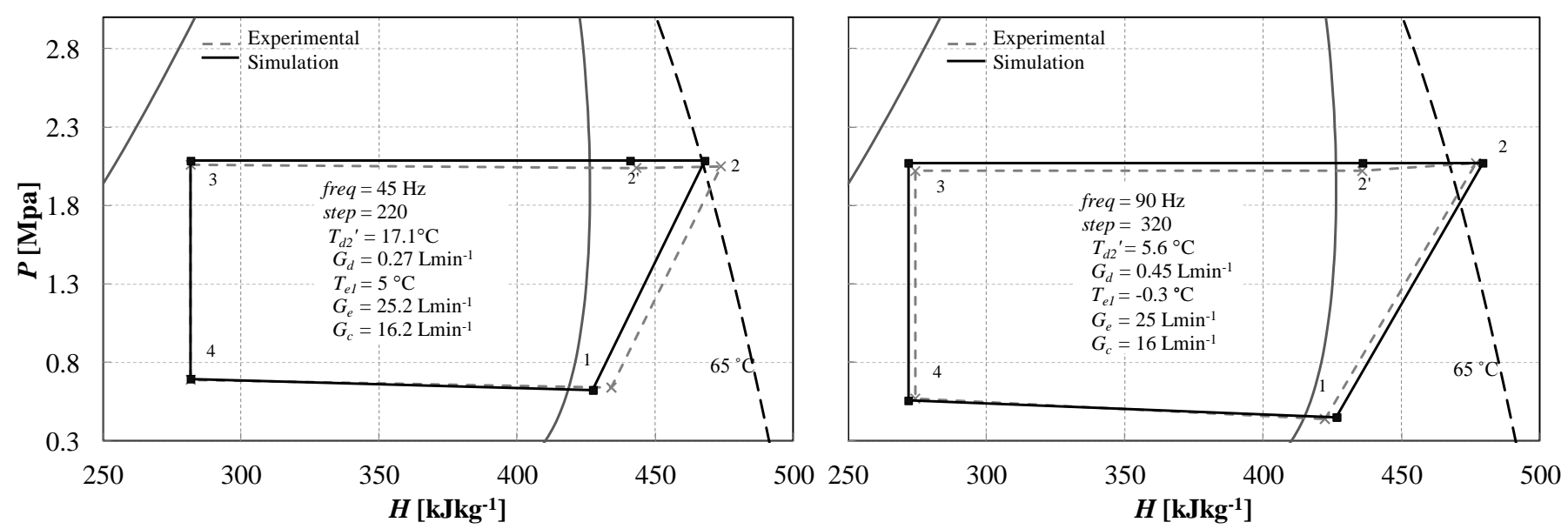

Fig. 7. Comparison between simulated and experimental refrigeration cycles in the PH diagram. 

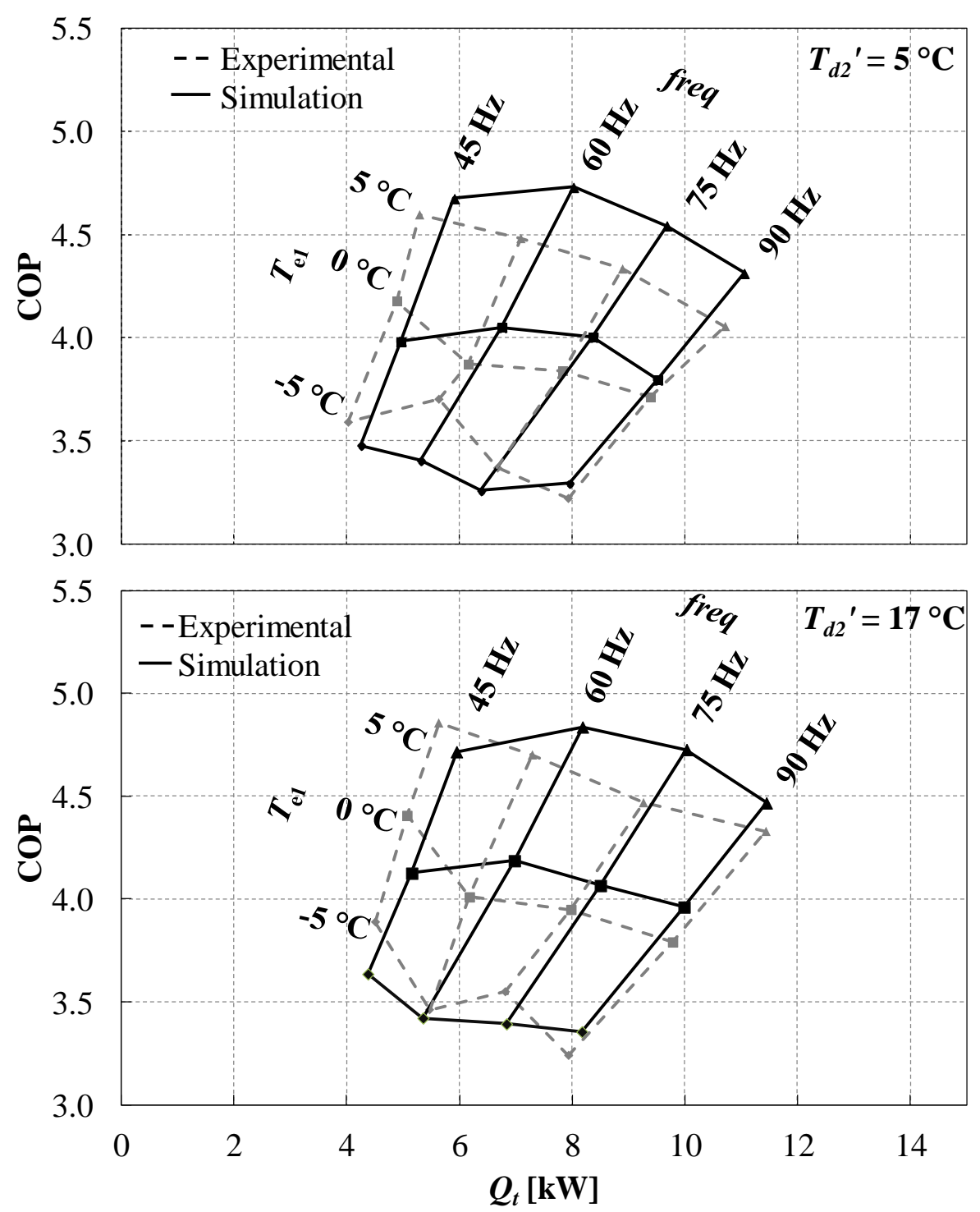

Fig. 8. Comparison of mapping results for $T_{d 2}{ }^{\prime}=5^{\circ} \mathrm{C}$ and $17^{\circ} \mathrm{C}$ between experimental and simulation results 


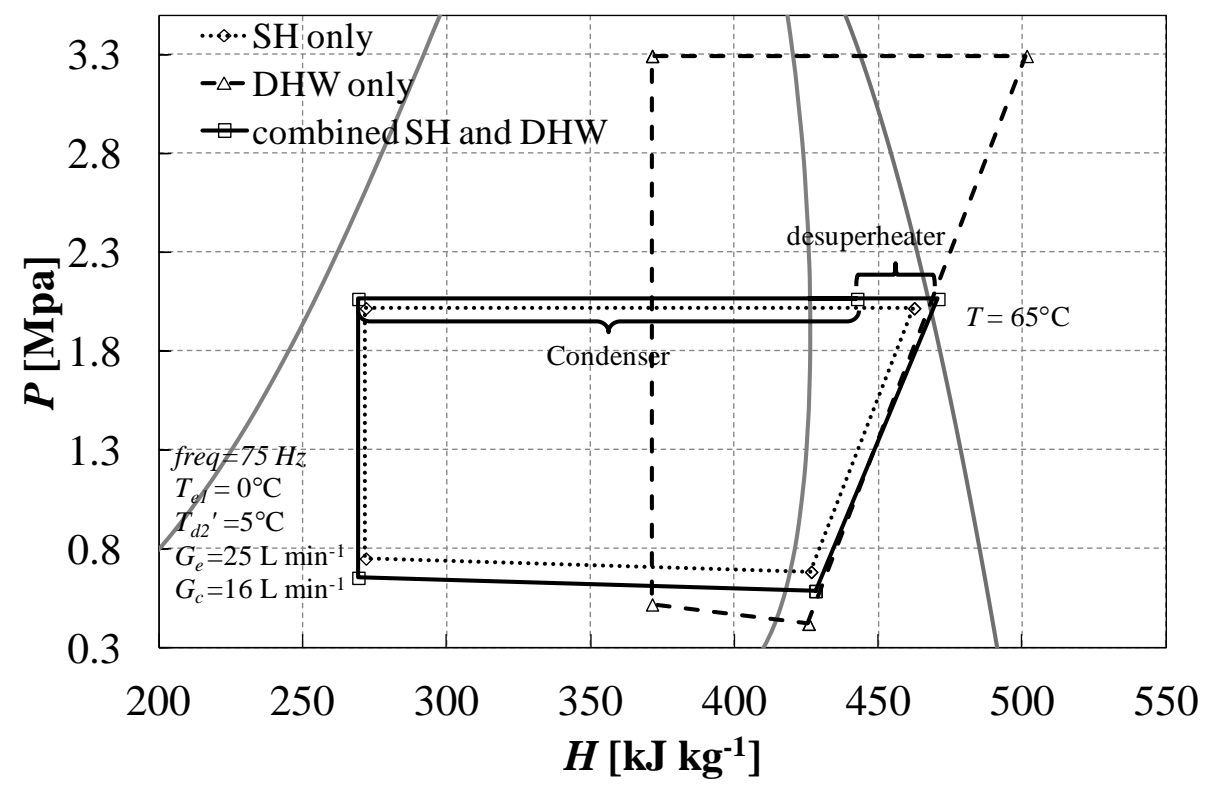

Fig. 9. Simulation results for the compact GSHP with a desuperheater for three of its operation modes under the same climate conditions 


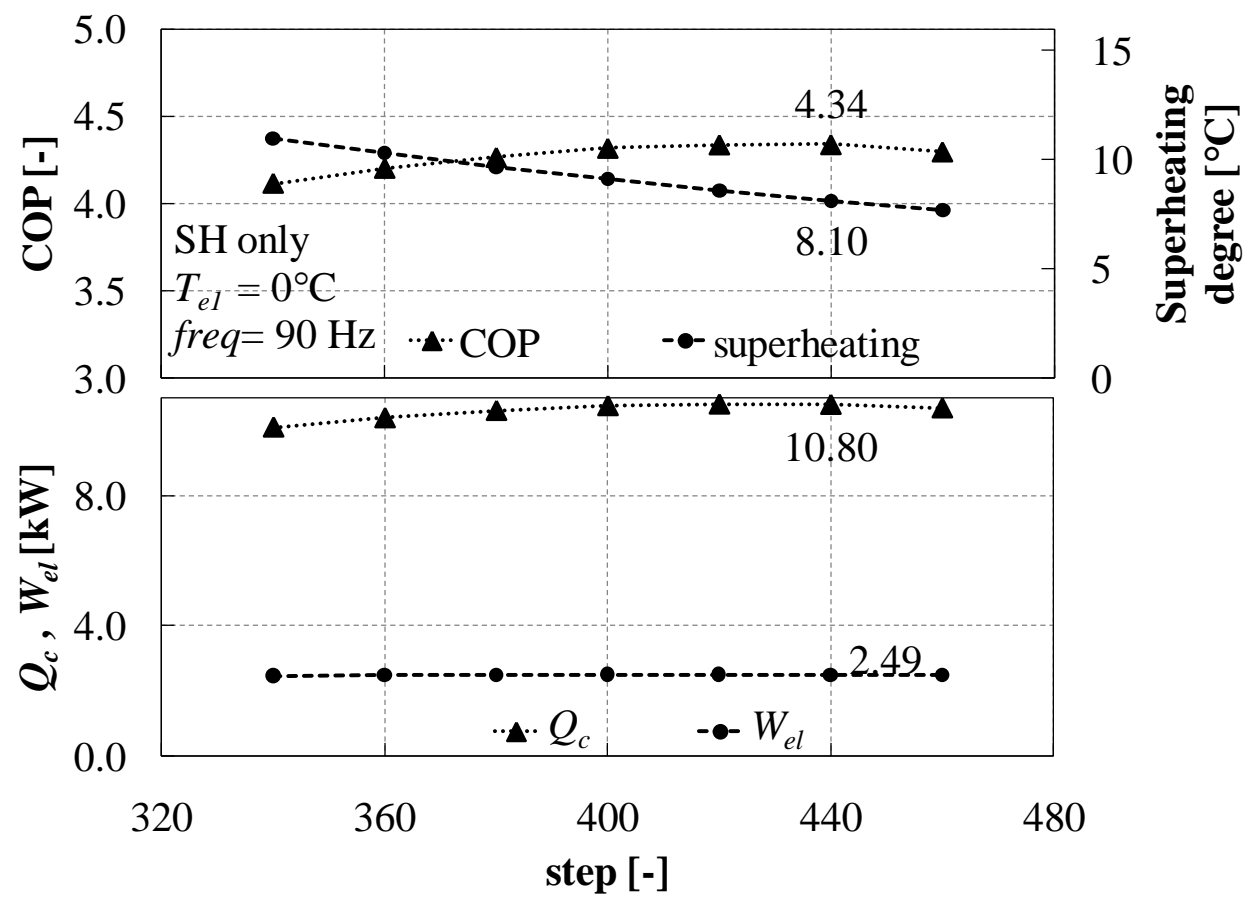

a) Space heating only

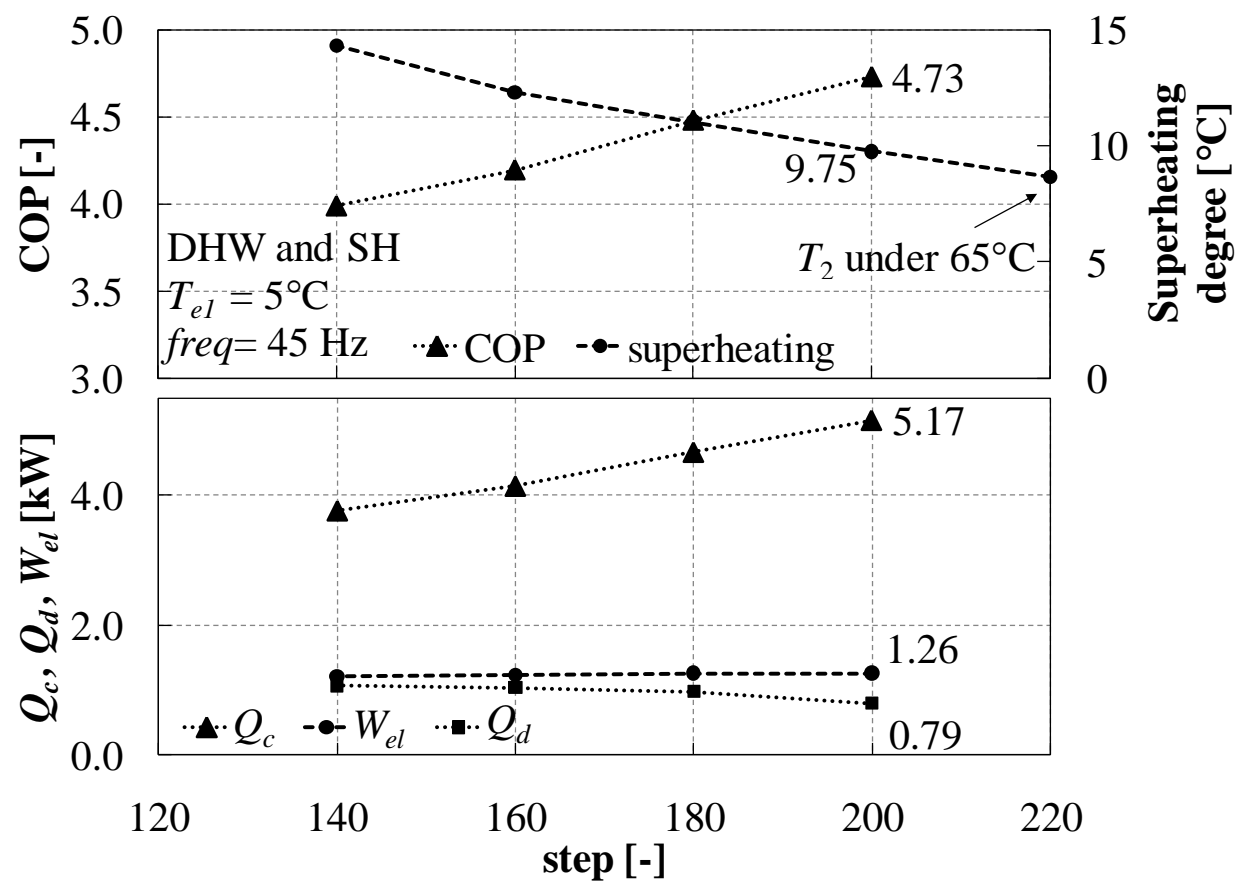

b) Combined space heating and domestic hot water

Fig. 10. Simulated superheating with expansion valve control 
Table 1. Selected vapor compression refrigeration cycle simulations

\begin{tabular}{|c|c|c|c|c|c|c|c|}
\hline Authors, year & Considerations & $\begin{array}{l}\text { System } \\
\text { analysis }\end{array}$ & $\begin{array}{l}\text { Compressor } \\
\text { speed }\end{array}$ & Heat exchangers models & $\begin{array}{l}\text { Expansion } \\
\text { device }\end{array}$ & $\begin{array}{l}\text { Convergence } \\
\text { technique }\end{array}$ & Simulation application \\
\hline $\begin{array}{l}\text { Hiller and } \\
\text { Glicksman } \\
(1976)\end{array}$ & $\begin{array}{l}\text {-Fixed superheating and subcooling } \\
\text { degrees } \\
\text {-Fixed evaporating temperature }\end{array}$ & Steady & Variable & $\begin{array}{l}\text {-No desuperheater } \\
\text { - Three and two zones for } \\
\text { the condenser and } \\
\text { evaporator, respectively }\end{array}$ & $\begin{array}{l}\text { - Thermostatic } \\
\text { expansion valve }\end{array}$ & -Dichotomizing search & -Performance evaluation \\
\hline $\begin{array}{l}\text { Fukushima, et } \\
\text { al. (1977) }\end{array}$ & $\begin{array}{l}\text { - Initial condensing/evaporating } \\
\text { pressures and enthalpy must be } \\
\text { specified prior to execution }\end{array}$ & Steady & Constant & $\begin{array}{l}\text {-No desuperheater } \\
\text { - Three and two zones for } \\
\text { the condenser and } \\
\text { evaporator, respectively }\end{array}$ & - Capillary tube & -Gradient descent & -Design of heat pump \\
\hline $\begin{array}{l}\text { Domanski and } \\
\text { Didion (1984) }\end{array}$ & $\begin{array}{l}\text {-Evaporator inlet quality, saturation } \\
\text { temperature and superheating degree } \\
\text { must be specified prior to execution }\end{array}$ & Steady & Constant & $\begin{array}{l}\text {-No desuperheater } \\
\text { - Three and two zones for } \\
\text { the condenser and } \\
\text { evaporator, respectively }\end{array}$ & - Capillary tube & $\begin{array}{l}\text {-Gradient descent } \\
\text {-Global search } \\
\text { algorithm }\end{array}$ & -Design of heat pump \\
\hline $\begin{array}{l}\text { Stefanuk et al. } \\
\text { (1992) }\end{array}$ & $\begin{array}{l}\text { - Evaporator inlet quality and } \\
\text { saturation temperature as well as } \\
\text { condensing temperature must be } \\
\text { specified prior to execution } \\
\text {-Fixed superheating degree }\end{array}$ & Steady & Constant & $\begin{array}{l}\text { - Three and two zones for } \\
\text { the condenser and } \\
\text { evaporator, respectively }\end{array}$ & $\begin{array}{l}\text {-Thermostatic } \\
\text { expansion valve }\end{array}$ & -Dichotomizing search & -Performance evaluation \\
\hline $\begin{array}{l}\text { Koury et al. } \\
(2001)\end{array}$ & $\begin{array}{l}\text { - Initial condensing/evaporating } \\
\text { pressures and superheating degree } \\
\text { must be specified prior to execution }\end{array}$ & $\begin{array}{l}\text { Steady and } \\
\text { transient }\end{array}$ & Variable & $\begin{array}{l}\text { - No desuperheater } \\
\text { - Distributed condenser } \\
\text { and evaporator models }\end{array}$ & $\begin{array}{l}\text { - Thermostatic } \\
\text { expansion valve }\end{array}$ & $\begin{array}{l}\text { - Simultaneous solver } \\
\text { method } \\
\text { - Successive } \\
\text { substitution }\end{array}$ & - Control of heat pump \\
\hline $\begin{array}{l}\text { Hui and Spitler } \\
\text { (2002) }\end{array}$ & $\begin{array}{l}\text { - Fixed superheating degree, no } \\
\text { subcooling degree } \\
\text { - Fixed heat transfer coefficients }\end{array}$ & Steady & Constant & $\begin{array}{l}\text { - No desuperheater } \\
\text { - Two zones for both } \\
\text { condenser and evaporator }\end{array}$ & - Not modeled & $\begin{array}{l}\text { - Simultaneous solver } \\
\text { method } \\
\text { - Multivariable } \\
\text { optimization }\end{array}$ & $\begin{array}{l}\text { - Performance evaluation based } \\
\text { on manufacturer data }\end{array}$ \\
\hline $\begin{array}{l}\text { Zhao et al. } \\
\text { (2003) }\end{array}$ & $\begin{array}{l}\text { - Zero subcooling or superheating } \\
\text { degrees } \\
\text { - Initial thermodynamic states of the } \\
\text { cycle's variables must be specified } \\
\text { prior to execution }\end{array}$ & Steady & Constant & $\begin{array}{l}\text { - No desuperheater } \\
\text { - Two and one zones for } \\
\text { the condenser and } \\
\text { evaporator, respectively }\end{array}$ & $\begin{array}{l}\text { - Thermostatic } \\
\text { expansion valve }\end{array}$ & $\begin{array}{l}\text { - Dichotomizing } \\
\text { search }\end{array}$ & - Evaluation of the system \\
\hline $\begin{array}{l}\text { Rigola et al. } \\
\text { (2005) }\end{array}$ & $\begin{array}{l}\text { - Fixed compressor discharged } \\
\text { pressure }\end{array}$ & $\begin{array}{l}\text { Steady and } \\
\text { transient }\end{array}$ & Constant & $\begin{array}{l}\text { - No desuperheater } \\
\text { - Distributed condenser }\end{array}$ & $\begin{array}{l}\text { - Fixed opening } \\
\text { expansion valve }\end{array}$ & $\begin{array}{l}\text { - Successive } \\
\text { substitution }\end{array}$ & $\begin{array}{l}\text { - Evaluation of reciprocating } \\
\text { compressors }\end{array}$ \\
\hline
\end{tabular}

Prepared by David Blanco, Katsunori Nagano and Masahiro Morimoto 
and evaporator models

\begin{tabular}{|c|c|c|c|c|c|c|c|}
\hline $\begin{array}{l}\text { Winkler et al. } \\
(2008)\end{array}$ & $\begin{array}{l}\text { - Multi-component framework } \\
\text { - Fixed subcooling degree } \\
\text { - Initial thermodynamic states of the } \\
\text { cycle's variables specified by running } \\
\text { each component prior to execution } \\
\text { - Fixed overall heat transfer } \\
\text { coefficients }\end{array}$ & Steady & Constant & $\begin{array}{l}\text { - No desuperheater } \\
\text { - Parallel evaporators } \\
\text { - Three and two zones for } \\
\text { the condenser and } \\
\text { evaporator, respectively }\end{array}$ & - No information & $\begin{array}{l}\text { - Non-linear } \\
\text { simultaneous equation } \\
\text { solver }\end{array}$ & $\begin{array}{l}\text { - Examination of simultaneous } \\
\text { algorithms effectiveness and } \\
\text { robustness }\end{array}$ \\
\hline $\begin{array}{l}\text { Belman et al. } \\
(2009)\end{array}$ & $\begin{array}{l}\text { - Fixed superheating degree } \\
\text { - Initial thermodynamic states of the } \\
\text { cycle's variables must be specified } \\
\text { prior to execution }\end{array}$ & Steady & Variable & $\begin{array}{l}\text { - No desuperheater } \\
\text { - Three and two zones for } \\
\text { the condenser and } \\
\text { evaporator, respectively }\end{array}$ & $\begin{array}{l}\text { - Thermostatic } \\
\text { expansion valve }\end{array}$ & $\begin{array}{l}\text { - Simultaneous solver } \\
\text { method }\end{array}$ & $\begin{array}{l}\text { - Parameter evaluation based on } \\
\text { manufacturer data }\end{array}$ \\
\hline $\begin{array}{l}\text { Our novel } \\
\text { model: }\end{array}$ & $\begin{array}{l}\text { - Multi-component framework (no } \\
\text { branching of refrigerant) } \\
\text { - Flexible superheating and } \\
\text { subcooling degree } \\
\text { - Initial thermodynamic states of the } \\
\text { cycle's variables derived transparently } \\
\text { from inlet conditions }\end{array}$ & Steady & Variable & $\begin{array}{l}\text { - Adaptable region models } \\
\text { for the three heat } \\
\text { exchangers (One, two or } \\
\text { three zones, depending on } \\
\text { the specific performance of } \\
\text { the system) }\end{array}$ & $\begin{array}{l}\text { - Controllable } \\
\text { opening } \\
\text { electronic } \\
\text { expansion valve }\end{array}$ & $\begin{array}{l}\text { - Multivariable error } \\
\text { minimization method }\end{array}$ & $\begin{array}{l}\text { - Evaluation at off-design } \\
\text { conditions } \\
\text { - Integration with ground and } \\
\text { load simulation tools for } \\
\text { calculation of realistic annual } \\
\text { performance factors } \\
\text { - Evaluation of control strategies }\end{array}$ \\
\hline
\end{tabular}


Table 2: Main input and output variables for each component

\begin{tabular}{rlr}
\hline & Input & Output \\
\hline Compressor & $\eta_{f r}, V_{s w}$, freq, $A_{0 \ldots,}, P_{1}, P_{2}, T_{1}$ & $W_{\mathrm{el}}, \dot{m}_{c o m p r}, H_{2}$ \\
Desuperheater & $P_{2}, T_{2}, T_{d 2}, C_{p d}, \dot{m}_{d}, \dot{m}$ & $Q_{d}, T_{d 2}$ \\
Condenser & $P_{2}, H_{2}{ }^{\prime}, T_{c 3}, C_{p c}, \dot{m}_{c}, \dot{m}$ & $Q_{c}, T_{c 2}{ }^{\prime}$ \\
Expansion Valve & $\eta_{\text {expv }}, A_{\max }, B_{0 \ldots 2}, \rho_{3 l}, P_{2}, P_{4}$ & $\dot{m}_{\text {exp }}$ \\
Evaporator & $P_{4}, H_{4}, T_{e l}, C_{p e}, \dot{m}_{e}, \dot{m}$ & $P_{1}, Q_{\mathrm{e}}, T_{e 4}$ \\
\hline
\end{tabular}

Prepared by David Blanco, Katsunori Nagano and Masahiro Morimoto 
Table 3: Refrigerant junction state for the modeled case for each heat exchanger, where the second and third letters denote the initial and final zones of the refrigerant in the heat exchanger (gas, mixed or liquid)

\begin{tabular}{crrr}
\hline Heat exchanger & Case & inlet junction & outlet junction \\
\hline \multirow{2}{*}{ Desuperheater } & DGG & 2 gas & 2' gas \\
& DGM & 2 gas & $2^{\prime}$ mix \\
& CGG & $2^{\prime}$ gas & 3 gas \\
& CGM & $2^{\prime}$ gas & 3 mix \\
Condenser & CGL & $2^{\prime}$ gas & 3 liquid \\
& CMM & $2 '$ mix & 3 mix \\
& CML & $2 '$ mix & 3 liquid \\
Evaporator & EMG & 4 mix & 1 gas \\
\hline
\end{tabular}


Table 4: Experimental conditions

\begin{tabular}{lcl}
\hline Component & Control variable & Values \\
\hline Compressor & freq & $45,60,75,90 \mathrm{~Hz}$ \\
Expansion valve & step & 80 to 480 \\
Condenser output & $T_{\mathrm{c} 2}{ }^{\prime}$ & $35^{\circ} \mathrm{C}$ \\
$\quad$ flow rate & $G_{\mathrm{c}}$ & $16 \mathrm{Lmin}^{-1}$ \\
Evaporator output & $T_{\mathrm{e} 1}$ & $-5,0,5^{\circ} \mathrm{C}$ \\
$\quad$ flow rate & $G_{\mathrm{e}}$ & $25 \mathrm{Lmin}^{-1}$ \\
Desuperheater & $T_{\mathrm{d} 2}{ }^{\prime}$ & $5,17,30^{\circ} \mathrm{C}$ \\
& $T_{\mathrm{d} 2}$ & $65^{\circ} \mathrm{C}$ \\
\hline
\end{tabular}

Prepared by David Blanco, Katsunori Nagano and Masahiro Morimoto 
Table 5: Simulated and experimental pressure and enthalpy values for selected experiments

\begin{tabular}{|c|c|c|c|c|c|c|}
\hline \multirow{2}{*}{$\begin{array}{c}\text { Condition } \\
T_{\mathrm{d} 2}{ }^{\prime} \\
T_{\mathrm{e} 1}-T_{\mathrm{c}^{\prime}}-T_{\mathrm{d} 2}\end{array}$} & \multirow[b]{2}{*}{ Junction } & \multicolumn{2}{|c|}{$P[$ Mpa $]$} & \multicolumn{2}{|c|}{$H\left[\mathrm{kJkg}^{-1}\right]$} & \multirow{2}{*}{ Relative Error [\%] } \\
\hline & & Exp. & Sim. & Exp. & Sim. & \\
\hline \multirow{5}{*}{$\begin{array}{c}17 \\
5-35-65\end{array}$} & 1 & 0.64 & 0.63 & 434.18 & 427.44 & 2.81 \\
\hline & 2 & 2.05 & 2.09 & 473.83 & 467.94 & 2.15 \\
\hline & $2^{\prime}$ & 2.04 & 2.09 & 443.22 & 440.94 & 2.31 \\
\hline & 3 & 2.06 & 2.09 & 281.80 & 281.74 & 1.26 \\
\hline & 4 & 0.69 & 0.70 & 281.80 & 281.74 & 0.88 \\
\hline \multirow{5}{*}{$\begin{array}{c}5 \\
0-35-65\end{array}$} & 1 & 0.44 & 0.45 & 422.31 & 426.54 & 2.90 \\
\hline & 2 & 2.07 & 2.07 & 476.94 & 479.34 & 0.51 \\
\hline & $2^{\prime}$ & 2.02 & 2.07 & 435.85 & 435.94 & 2.57 \\
\hline & 3 & 2.02 & 2.07 & 274.3 & 271.74 & 2.74 \\
\hline & 4 & 0.57 & 0.56 & 274.3 & 271.74 & 2.37 \\
\hline
\end{tabular}

